\title{
Non-invasive study of natural dyes on historical textiles from the collection of Michelangelo Guggenheim
}

\author{
L. de Ferri ${ }^{\mathrm{a}, 1}$, R. Tripodi ${ }^{\mathrm{b}, 1}$, A. Martignon ${ }^{\text {a }}$, E.S. Ferrari ${ }^{\mathrm{a}, 2}$, A.C. Lagrutta-Diaz $^{\mathrm{a}, 2}$, D. Vallotto ${ }^{\text {a }}$, G. Pojana ${ }^{\mathrm{a}, *}$ \\ a Department of Philosophy and Cultural Heritage, University Ca' Foscari of Venice, Dorsoduro 3484/d, I-30123 Venice, Italy \\ bepartment of Management, University Ca' Foscari of Venice, San Giobbe, Cannaregio 873, Venice I-30121, Italy
}

\section{A R T I C L E I N F O}

\section{Article history:}

Received 30 January 2018

Received in revised form 30 May 2018

Accepted 7 June 2018

Available online 15 June 2018

\section{Keywords:}

Natural dyes

Historical fabrics

Reflectance spectroscopy

Clustering

Silk

\begin{abstract}
A B S T R A C T
A selection of historical textile fragments from the Venetian art dealer Moisè Michelangelo Guggenheim collection, ranging from XV to XVIII century, has been investigated by means of non-invasive techniques in order to reveal the coloring materials. Imaging was preliminarily used to visually investigate the selected artwork fragments in order to investigate their structure and conservation conditions; Fiber Optics Reflectance Spectroscopy (FORS) allowed recognizing the main natural dyestuffs, such as indigotin and anthraquinones-based compounds, except the yellow ones, difficultly identifiable when using this non-invasive technique. Collected spectroscopic data have been also elaborated by using a clustering algorithm that permitted to group collected spectra on the basis of similar properties and evidencing their inflection point wavelength as the most influencing feature.
\end{abstract}

(C) 2018 Elsevier B.V. All rights reserved.

\section{Introduction}

A non-invasive approach for the study of historical artworks typically employs a set of spectroscopic techniques, such as diffuse reflectance spectroscopy, with particular reference to the variant with optical fibers or FORS (Fiber Optic Reflectance Spectroscopy). This is a very suitable, easy to apply and fast technique for the analysis of polychrome objects, considerable as a preliminary tool to be employed before more sophisticated, usually micro-destructive, analytical methods.

Reflectance Spectroscopy, especially in the FORS configuration, is a well-established technique for the characterization of natural dyes in artworks: many applications were reported for paintings and frescoes [1-3], manuscripts [4,5] and fabrics [6-11]; this method is becoming a useful analytical tool for conservation scientists in textiles examination, dyes identification, as testified by the very recent paper by MaynezRojas et al., presenting a complete FORS study for the identification of red dyestuff in historical fabrics [12], and to provide preliminary data useful for developing conservation strategies $[10,11]$. The FORS technique, totally non-destructive and non-invasive, also allows limiting the sampling.

Despite all listed advantages, some drawbacks unfortunately prevent to apply this technique as a unique analytical tool for the characterization of natural dyes in historical fabrics: reflectance spectra usually

\footnotetext{
* Corresponding author.

E-mail address: jp@unive.it (G. Pojana).

1 These authors contributed equally to the research.

2 These authors contributed equally to the research.
}

exhibit broad bands with a lower fingerprinting potential which cannot allow unambiguous identification of compounds, with respect to other molecular spectroscopic techniques, such as Raman or FT-IR. This is particularly true when two or more absorbing substances are present in the investigated area, as in the case of mixtures, or when their spectral features are modified by other parameters.

Some literature studies already report spectral variations due to the substrate nature (linen, cotton, silk, wool, etc.) [13] and to ageing processes [14,15], which can also affect the colorants [7,15]; the use of different dyeing techniques and mordants $[11,13,16,17]$ can also act a very important role in affecting FORS spectra. Table 1 reports a summary of possible combinations of dyes and mordants exhibiting different hues. As a general rule, the visible electromagnetic spectrum provides information related to the electronic transitions of dyeing molecules for colored textiles, and it is therefore the most significant interval for their recognition, whereas distinctive profiles of supporting fibers are mainly recorded in the Near Infra-Red (NIR) range $[10,11]$.

In this work a quite heterogeneous set of historical fabrics (Figs. 1-3, high resolution images of all fragments available as Supplementary material in Figs. 1S-44S) from Michelangelo Guggenheim fabrics collection, mainly silk-based, belonging to various historical periods (XVXVIII Century) and categories, and in dissimilar conservation conditions, were selected from a wider historical collection (see Section 2.1) and studied. Textile fragments were preliminary carefully investigated by high resolution imaging and then analyzed by FORS for a tentative identification of dyes applied.

Obtained spectral data were furthermore elaborated by means of clustering analysis to better distinguish colorants exhibiting similar 
Table 1

Summary of the main natural colorants used for fabric dyeing.

(Adapted from [16])

\begin{tabular}{|c|c|c|c|c|c|c|c|}
\hline Name & Latin name & Origin & Used part & Chromophore & Dye technique & Fibers & Mordant, additives and shades \\
\hline Cochineal & $\begin{array}{l}\text { Dactylopius } \\
\text { coccus cacti L. }\end{array}$ & Mexico, Guatemala, Algeria & Female insect & Carminic acid & Mordant dye & Wool, silk & $\begin{array}{l}\text { Alum: bright red } \\
\text { Copper: purplish red } \\
\text { Chromium: purple } \\
\text { Iron: purple } \\
\text { Tin: scarlet }\end{array}$ \\
\hline Kermes & Coccus ilicis L. & Persia, Spain, North Africa & & Kermesic acid & & & \\
\hline Madder & $\begin{array}{l}\text { Rubia tinctoria } \\
\text { L. }\end{array}$ & Asia; farmed in Europe & Roots & $\begin{array}{l}\text { Alizarin and } \\
\text { purpurin }\end{array}$ & Mordant dye & $\begin{array}{l}\text { Wool, silk, } \\
\text { cotton }\end{array}$ & $\begin{array}{l}\text { Alum: all scarlet shades } \\
\text { Copper: dark yellow } \\
\text { Chromium: dark purple } \\
\text { Iron: light purple } \\
\text { Tin: pink }\end{array}$ \\
\hline Brazilwood & $\begin{array}{l}\text { Caesalpinia } \\
\text { brasiliensis L. }\end{array}$ & $\begin{array}{l}\text { Brasil, Africa, Eastern India, Ceylon, } \\
\text { Japan }\end{array}$ & $\begin{array}{l}\text { cortex, wood } \\
\text { without sapwood }\end{array}$ & Brazilein & Mordant dye & Wool & $\begin{array}{l}\text { Alum: orange red } \\
\text { Sumac or iron: brown } \\
\text { Often coupled with other red } \\
\text { colorants }\end{array}$ \\
\hline Safflower & $\begin{array}{l}\text { Carthamus } \\
\text { tinctotum } \mathrm{L} .\end{array}$ & Europe, Russia, Persia, South Asia & Corolla & Carthamin & Direct dye & $\begin{array}{l}\text { Silk, } \\
\text { cotton }\end{array}$ & Yellow \\
\hline Weld & Reseda luteola $\mathrm{L}$. & $\begin{array}{l}\text { Center Europe, farmed in France, } \\
\text { Germany, England }\end{array}$ & $\begin{array}{l}\text { Everything except } \\
\text { for the roots }\end{array}$ & Luteolin & Mordant dye & Wool, silk & $\begin{array}{l}\text { Alum or tin or cream of tartar: } \\
\text { various shades of yellow } \\
\text { Alum and iron: beige }\end{array}$ \\
\hline Curcuma & $\begin{array}{l}\text { Curcuma longa } \\
\text { L. }\end{array}$ & $\begin{array}{l}\text { Tropical Asia, South Africa, Central } \\
\text { America, Brasil, Antille }\end{array}$ & Roots & Curcumin & $\begin{array}{l}\text { Direct and } \\
\text { mordant dye }\end{array}$ & $\begin{array}{l}\text { Wool, silk, } \\
\text { cotton }\end{array}$ & $\begin{array}{l}\text { Alum: orange yellow } \\
\text { Copper: orange red } \\
\text { Chromium: brown } \\
\text { Iron: black/brown }\end{array}$ \\
\hline Saffron & Crocus sativus L. & $\begin{array}{l}\text { Southern Europe, Persia, } \\
\text { Afghanistan, Cashmere }\end{array}$ & Dried stigmas & Crocetin & Direct dye & Wool, silk & $\begin{array}{l}\text { Alum: dark orange } \\
\text { Tin: dark yellow }\end{array}$ \\
\hline Quercitron & $\begin{array}{l}\text { Quercus } \\
\text { tinctoria } \mathrm{L} .\end{array}$ & Northern America & $\begin{array}{l}\text { Cortex, wood } \\
\text { without sapwood }\end{array}$ & Quercitrin & Mordant dye & Wool & $\begin{array}{l}\text { Alum or tin or chromium or iron: } \\
\text { different shades of yellow }\end{array}$ \\
\hline \multirow[t]{2}{*}{$\begin{array}{l}\text { Sicilian } \\
\text { sumac }\end{array}$} & Rhus coriaria L. & Mediterranean countries & Branch cortex & Fisetin & Mordant dye & Wool, silk & $\begin{array}{l}\text { Alone: yellow } \\
\text { Iron: from brown to black } \\
\text { Copper: from brown to black }\end{array}$ \\
\hline & & & $\begin{array}{l}\text { Root cortex and } \\
\text { leaves }\end{array}$ & Tannins & & & $\begin{array}{l}\text { Alone: from brown to black } \\
\text { Iron: grey, black } \\
\text { Galls or vitriol: black }\end{array}$ \\
\hline \multirow[t]{2}{*}{$\begin{array}{l}\text { Dyer's } \\
\text { sumac }\end{array}$} & Rhus cotinus L. & $\begin{array}{l}\text { Italy, Spain, Turkey, Hungary, } \\
\text { Dalmatia, Jamaica }\end{array}$ & Wood & Fisetin & Mordant dye & Wool & $\begin{array}{l}\text { Alum: orange red } \\
\text { Tin: orange } \\
\text { Iron: grey, black, olive green }\end{array}$ \\
\hline & & & Leaves & Tannins & & & $\begin{array}{l}\text { Alone: from brown to black } \\
\text { Iron: grey, black }\end{array}$ \\
\hline Indigo & $\begin{array}{l}\text { Indigofera } \\
\text { tinctoria } \mathrm{L} .\end{array}$ & India, America & Leaves & Indigotin & Vat dyes & Wool, silk & $\begin{array}{l}\text { Alum or arsenic sulphur: all shades of } \\
\text { blue }\end{array}$ \\
\hline Woad & Isatis tinctoria $\mathrm{L}$. & Europe & & & & & \\
\hline
\end{tabular}

hues. This approach allow to automatize the colorant identification process and to conduct analysis at group level, which can be very useful when the available number of spectra is relatively large (hundreds/ thousands), or when the sample set is relatively heterogeneous, as in this case, with various historical fabrics that were subjected to different degradation processes.

In addition, visual inspection of images acquired in the NIR (900-1200 nm) spectral range was also employed to extend the investigated spectral range. All obtained data are aimed to support a wider project for the valorization of the investigated collection.

\section{Materials and Methods}

\subsection{The Michelangelo Guggenheim Collection}

Moisè Michelangelo Guggenheim (Venice, 17th November 1837-21st September 1914) was the greatest antique dealer of Venice in the second half of the XIX century [18-20], becoming the stereotype of the Venetian antique dealer to the eyes of foreigners. He also was a collector, an entrepreneur, an interior and decorative art objects designer, a promoter of industrial art education [21], a connoisseur, a historian, a consultant, an expert, an agent, a mediator, a patron, a philanthropist and a politician ([22], Martignon A, Michelangelo Guggenheim, l'eclettico antiquario di Venezia. Vita ed opera di un protagonista dell'Otto-Novecento, Il Poligrafo, Padova, in editing, and its updated bibliography).

His famous antique art gallery, together with his collection and a workshop of decorative art objects, was hosted for decades in Balbi Palace, a late XVI century building facing the Grand Canal $[23,24]$ normally frequented by prestigious Italian and foreign collectors and by agents from public galleries, auction houses, antique and modern art galleries, and European and American companies [22]. The Guggenheim eclectic collection was composed by paintings, sculptures, terracotta models, plaster casts, stone and bronze artifacts, furniture and especially by decorative art objects, as railings, majolicas, glass objects, jewels, wooden objects (mainly frames), engravings, printings, drawings, books, manuscripts, documents and photographs [22]. A section specifically committed to textiles and laces [25] was exposed in a reserved room [24] on Balbi Palace first noble floor. They were applied on a thin pasteboard equipped with hooks, necessary to hang them on the walls, and were often surrounded by a passe-partout covered by a glass.

Guggenheim was a connoisseur of European and Middle Eastern weaving techniques, textiles and dresses historical evolution over centuries and was particularly able to distinguish and compare diverse productions. Besides buying textiles, laces, dresses, accessories, carpets, tapestries and other ancient textile-based artifacts for his own collection and gallery (for selling to famous museums and collectors [26] such as Isabelle Alice Errera of the Royal Museums of Decorative Arts of Brussels $[27,28])$, he worked also as consultant for important museum 


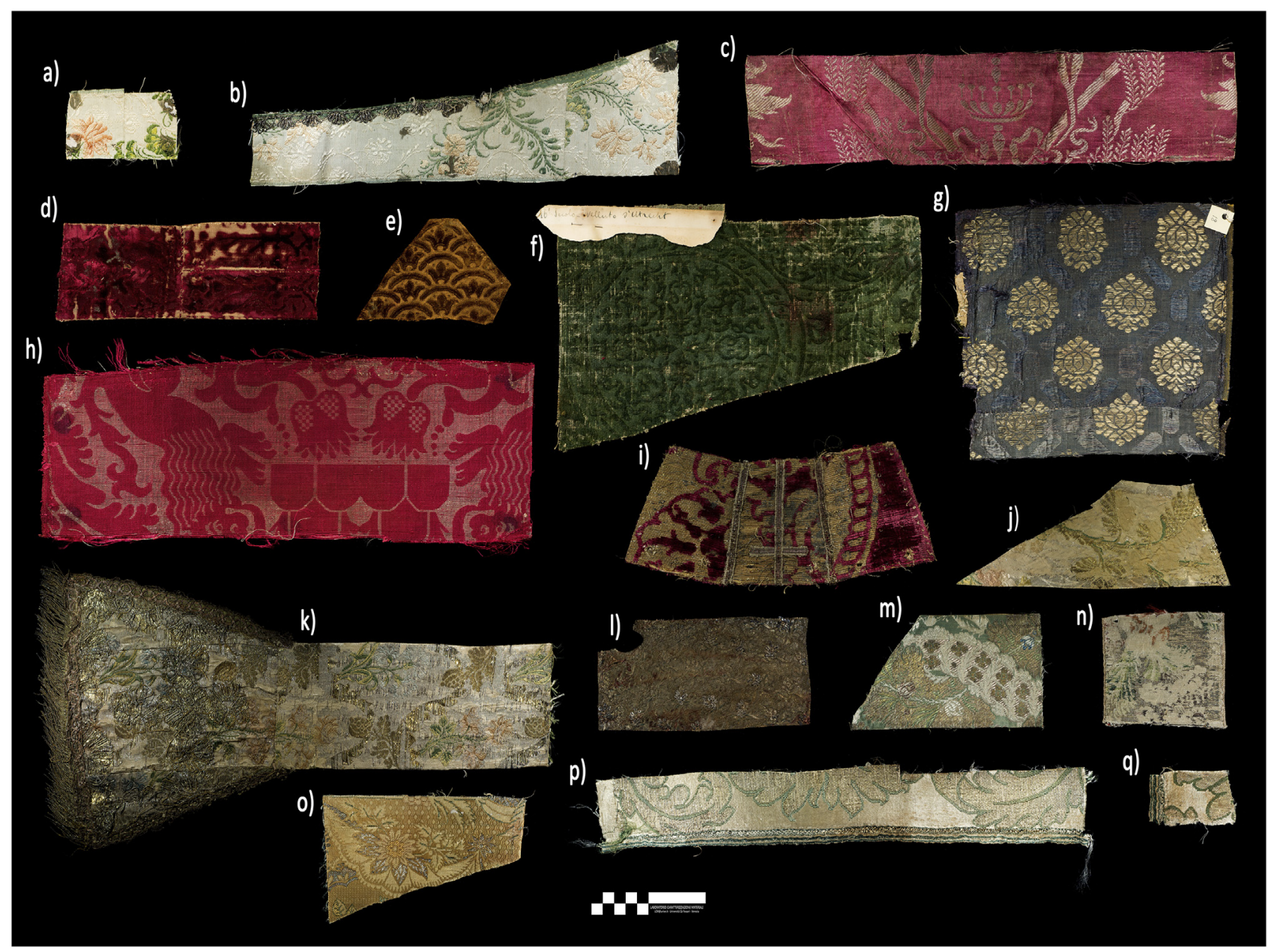

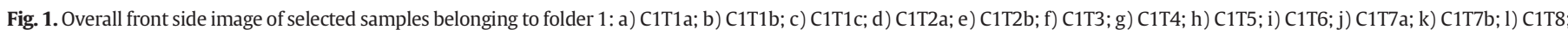
m) C1T9a; n) C1T9b; o) C1T9c; p) C1T9d; q) C1T9e.

institutions such as the Estense Museum of Modena [29], for collectors such as Lady Mary Enid Evelyn Guest in Layard [30-32], and for antique dealers such as Leopold Stern from Munich [33]. In addition he also designed the setting up and furnishing of Coccina Tiepolo Papadopoli Palace in Venice by providing modern tapestries, curtains and carpets from renowned French factories [34].

Although a complete inventory of Guggenheim textile collection is not currently available, a large part of its original appearance can be reconstructed thanks to all pieces exhibited during the "Exposition of textiles and laces" held in Rome in 1887 (103 pieces) [35], to the textile fragments donated to Correr Museum of Venice (about 350 pieces) [36-42], to the fabric fragments provided to Antiques Museum of Trieste (50 pieces) [43-45] and to the 140 textile fragments donated to Venetian School of Art applied to Industry that he contributed to found in 1872. Such enormous collection original appearance can be reconstructed also thanks to other fabric fragments and objects currently owned by his heirs ( 10 pieces) and to an (unpublished)inventory of textiles kept in the family's archive (143 pieces) [46].

All currently available information lead to conclude that Guggenheim's collection consisted of textiles ranging from the IV-V to the XIX century, together with laces, embroideries, tassels, embellishments, borders and clothes, as well as other accessories and artifacts made with textile inserts, mostly velvets ranging from the XVI and XVII centuries.

The building of such large collection was functional to his idea of displaying by means of textile fragments the evolution of textile art over centuries, and changes of decorative motifs. The preference for "alta epoca" velvets (a precious textile typology in its maximum splendor period) coming from Venice manufacturers, or of Venetian origin according to Guggenheim himself, was coherent with his educative program under development, based on an aesthetical education to be achieved by studying and imitating best examples from the past. He focused particularly on Venetian ones in orderto revive the local artistic industries strongly encouraging the study of his collection and of historical fabrics in general by both artisans and researchers. He made numerous donations to museums and schools for this purpose, and commissioned to local factories textiles and laces inspired by historical styles, generally based on his own design, for example for Coccina Tiepolo Papdopoli Palace [34,47].

In this work we propose the study of some fabric fragments belonging to the wide collection donated by Michelangelo Guggenheim to the Venetian School of Art applied to Industry (currently "Michelangelo Guggenheim" Art High School of Venice). The selected collection is constituted by velvets, brocades, brocatelles, damasks, lampasses, satins, gros and taffetas, datable back between the XV and the XVIII centuries, mostly attributable to Venice and Italian manufacturers.

\subsection{Analytical methods}

\subsubsection{Macro-photography}

All digital pictures have been recorded at ratio $1.1(3.6 \times 2.4 \mathrm{~cm}$ subject size) with a Nikon D800e digital camera coupled with a Zeiss lens Makro-Planar $100 \mathrm{~mm} \mathrm{f/2.8} \mathrm{on} \mathrm{a} \mathrm{macro} \mathrm{repro} \mathrm{stand,} \mathrm{at} \mathrm{ISO100,} \mathrm{f8} \mathrm{aper-}$ ture and shutter speed between $1 / 2$ and $1 / 16 \mathrm{~s}$. White and color calibrations have been performed for each picture by using a ColorChecker Passport panel and X-Rite software (Grand Rapids, MI, US). 

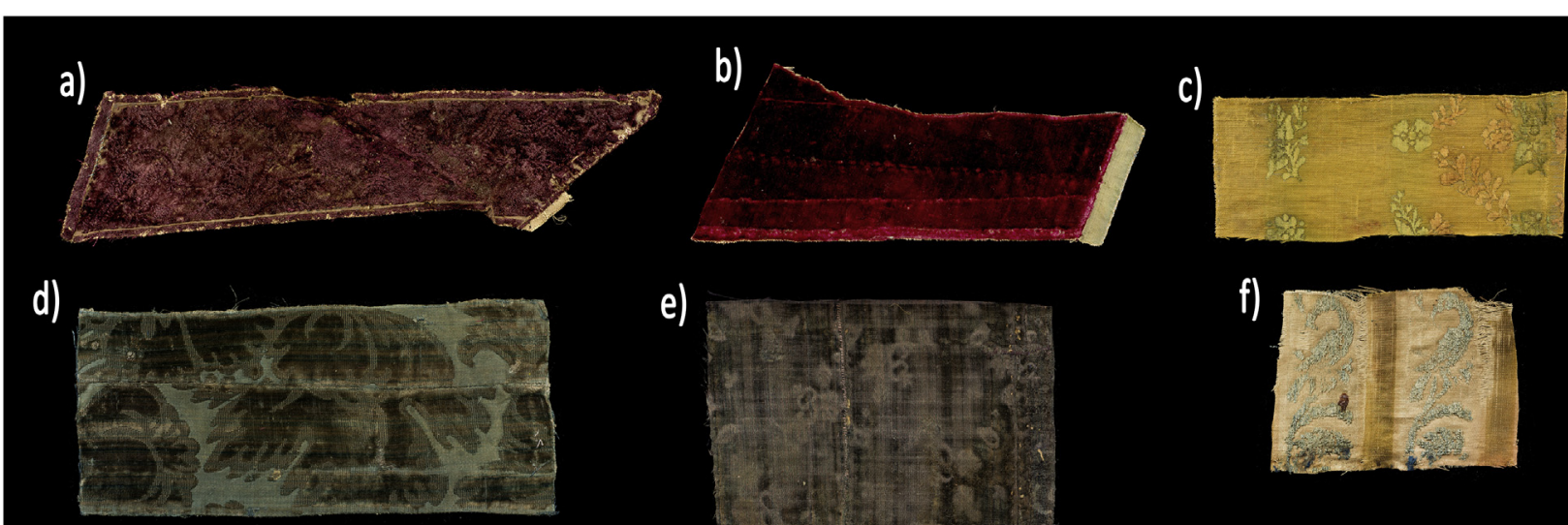

e)
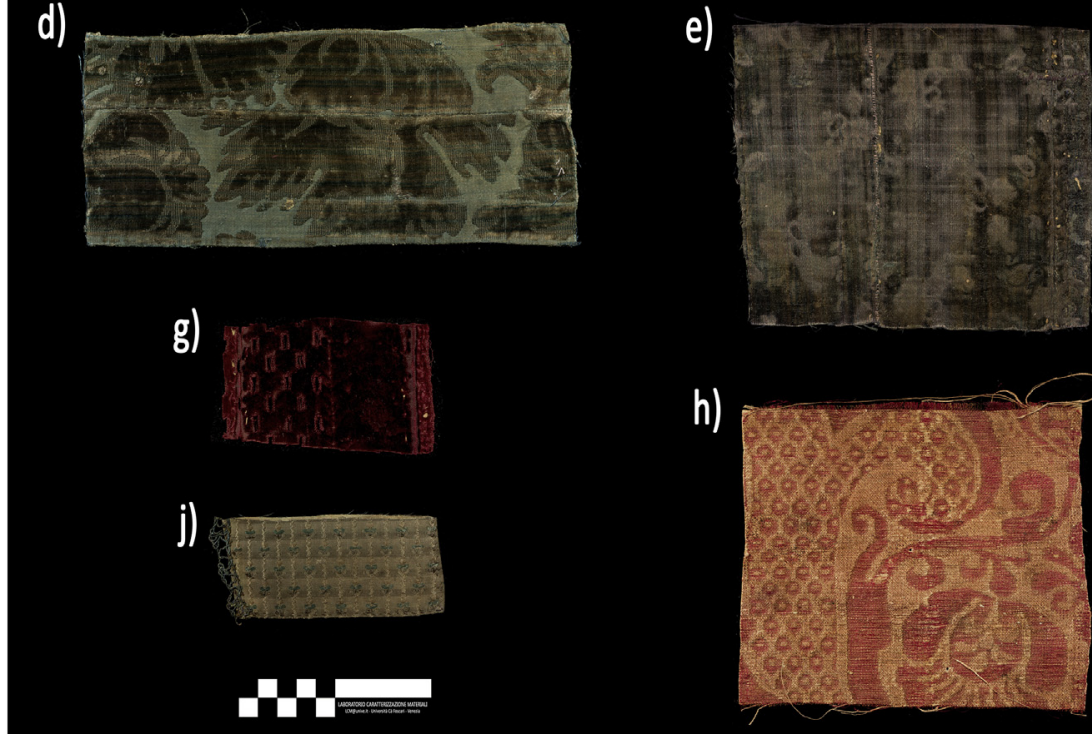

f)
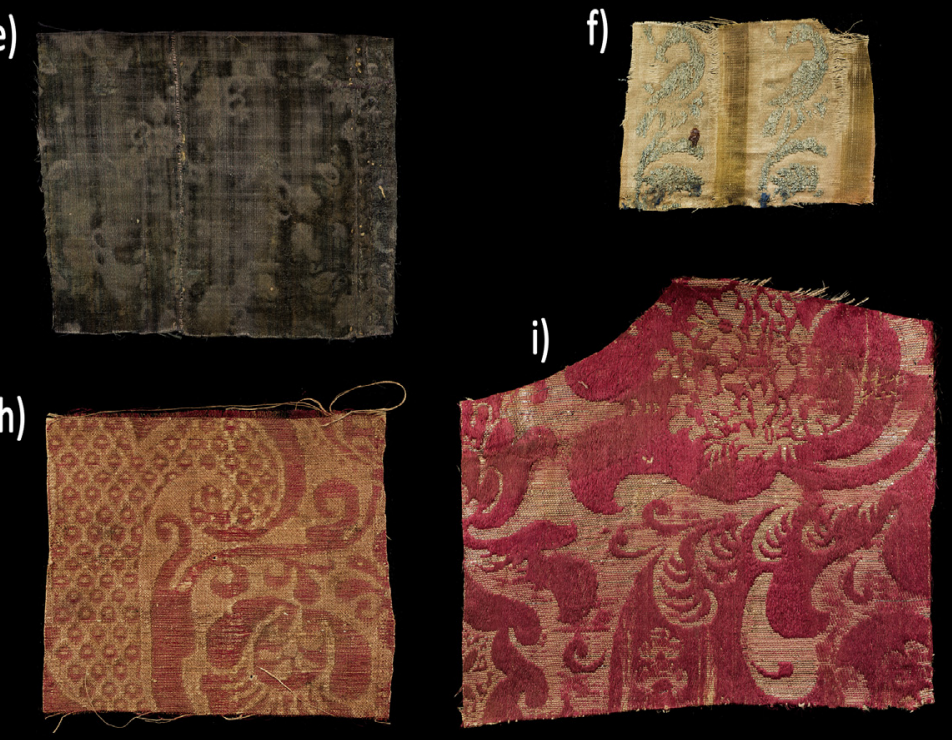

Fig. 2. Overall front side image of selected samples belonging to folder 2: a) C2T1; b) C2T2; c) C2T3; d) C2T4; e) C2T5; f) C2T6; g) C2T7; h) C2T8; i) C2T9; j) C2T10.

During image collection both shot and focus have been remotecontrolled from a PC by Camera Control Pro2 software by Nikon (Tokyo, Japan). Pictures have been collected on both front and on back sides of each fabric fragment, in order to evaluate their state conservation conditions.

\subsubsection{Reflectance Spectroscopy}

Reflectance spectra have been collected by using a portable fiber optic spectrophotometer Quest U by B\&W Tek Inc. (Newark, DE, USA), connected to a tungsten light source through a Y-shaped silica glass fiber bundle. It totally contains 7 fibers $(\varnothing=200 \mu \mathrm{m}$ each) entering a SMA 905 model reflection probe with a $0.28 \mathrm{~mm}^{2}$ collecting spot, 6 fibers illuminating the sample and 1 collecting the signal. Light is guided and focused on an aligned and optically matched slit ( $25 \mu \mathrm{m}$, leading to an optical resolution of approx. $1.5 \mathrm{~nm}$ ). A system of focusing $\mathrm{AlMg}_{2}$ coated mirrors allows the collimation and redirection of the light beam toward the grating and then to a refocusing mirror addressing the light to a 2048 pixel linear silicon CCD array detector.

Spectra were collected for each color on both fragment sides in the 370-950 nm interval avoiding areas affected by mildews, widely present of many fragments; a 99\% Teflon diffuse reflectance metrological standard from Labsphere (North Sutton, NH, US) was employed for calibration. Each spectrum was collected averaging 250 cycles of 12-42 ms each to enhance the signal/noise ratio, keeping both incident and acquisition angles at $45^{\circ}$ from the surface normal, in order to not include the specular reflection component while maintaining the probe perpendicular to the tread axis in order to maximize the signal. The instrument was connected to a PC controlled by means of the dedicated software (BWSpec4 by B\&W Tek) for spectra acquisition and colorimetric data collection. All collected spectra were normalized to $100 \%$ reflectance.
$\mathrm{L}^{*} \mathrm{a}^{*} \mathrm{~b}^{*}$ coordinates were extracted for each sample and applied to calculate the chroma value ( $C^{*}$, Eq. (1))

$C^{*}=\sqrt{a^{* 2}+b^{* 2}}$

as well as color difference values for couples of corresponding points taken on both fragment sides [48]. $\Delta \mathrm{E}^{*}$ was evaluated both as $\Delta \mathrm{E}_{76}{ }^{*}$ and $\Delta \mathrm{E}_{94}{ }^{*}$ (Eqs. (2) and (3)) since the 1994 formula, defined in the $\mathrm{L}^{*} \mathrm{C}^{*} \mathrm{~h}^{*}$ color space, was extended to address perceptual nonuniformities by applying specific weight derived by tolerance tests.

$\Delta E_{76}{ }^{*}=\sqrt{\left(L_{2}^{*}-L_{1}^{*}\right)^{2}+\left(a_{2}^{*}-a_{1}^{*}\right)^{2}+\left(b_{2}^{*}-b_{1}^{*}\right)^{2}}$
$\Delta E_{94}{ }^{*}=\sqrt{\left(\frac{L_{2}^{*}-L_{1}^{*}}{k_{L} S_{L}}\right)^{2}+\left(\frac{C_{2}^{*}-C_{1}^{*}}{k_{C} S_{C}}\right)^{2}-\left(\frac{\Delta H^{*}{ }_{a b}}{k_{H} S_{H}}\right)^{2}}$

where $\mathrm{S}_{\mathrm{L}}=1, \mathrm{~S}_{\mathrm{C}}=1+\mathrm{K}_{1} \mathrm{C}^{*}$ and $\mathrm{S}_{\mathrm{H}}=1+\mathrm{K}_{2} \mathrm{C}^{*}{ }_{1}$, Being $\mathrm{K}_{1}=0.048$ and $\mathrm{K}_{2}=0.014$ for textiles.

When various points (from 2 to 4 ) for every color were analyzed, $\Delta \mathrm{E}^{*}$ average values were obtained, reported together with their standard deviation values $(\sigma)$.

\subsubsection{Reflected-NIR Photography}

Near Infra-Red (NIR) images were collected with a Samsung NX1100 camera modified in the $900-1150 \mathrm{~nm}$ spectral range by means of a Hoya (Kenko Tokina Ltd., Tokyo, Japan) RM90 IR pass filter. Textile samples were illuminated by an incandescent tungsten lamp.

\subsubsection{Clustering Analysis}

The clustering analysis was performed using the dominant set technique [49]. It is part of a class of algorithms based on game theoretic 


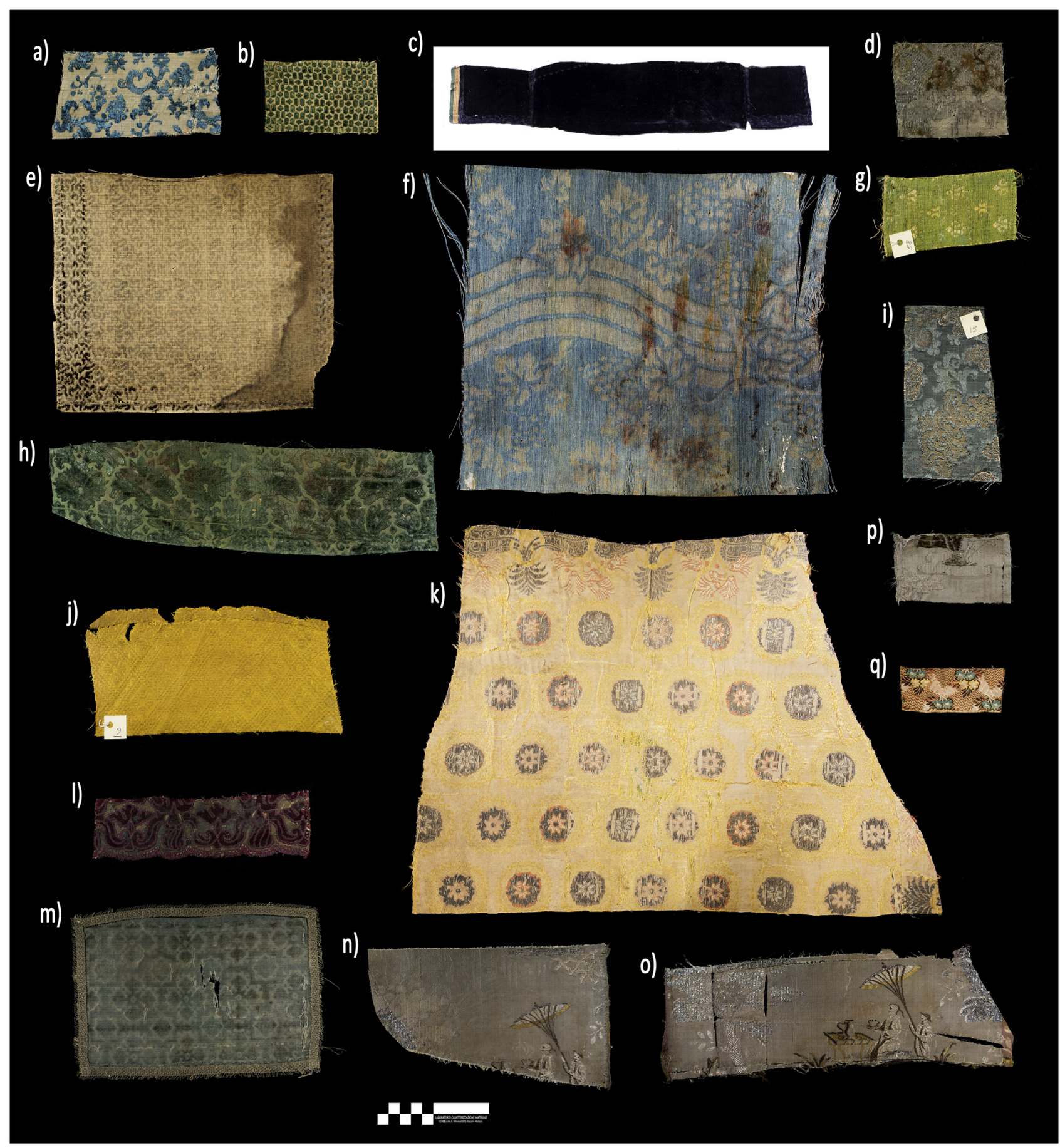

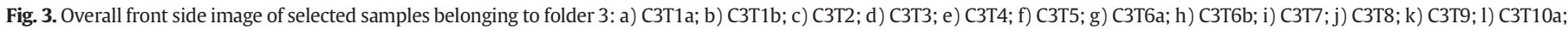
m) C3T10b; n) C3T11a; o) C3T11b; p) C3T11c; q) C3T12.

principles that in recent years were successfully applied to different pattern recognition and classification tasks [50,51]. This algorithm treats the objects to be clustered as nodes of a weighted graph, G. Graph weights can be calculated by means of similarity functions for each pair of objects in the dataset. Once the graph is constructed the algorithm extracts, sequentially, coherent groups of nodes from it, strictly corresponding to the maximal cliques of the graph and containing highly similar objects, being a $k$-clique a group of $k$ nodes in a graph in which each pairs of nodes are connected; a maximal clique is a $k$ clique that cannot be expanded ( $k$ cannot be increased). As a consequence the algorithm models the well-accepted definition of a cluster, stating it should have high internal homogeneity and that a high inhomogeneity degree should exist between objects inside and outside the cluster [52]. The extraction of compact structures from graphs reflecting both conditions is given by the following quadratic function (Eq. (4)):

$f(x)=x^{T} A x$

where $A$ is the adjacency matrix of the graph that encodes the similarity information among each pair of data points and $x$ is a probability vector, whose components indicate the participation of each node to a cluster. In this context, the clustering task equals to finding a vector $x$ that 
maximizes $f$, that can be done by the following instructions set:

minimize $f(x)$

subject to $x \in \Delta$

where $\Delta$ represents the standard simplex. A solution of this program corresponds to a maximally cohesive structure in the graph and its solution can be found using the discrete time version of the replicator dynamic equation [53], computed as follows (Eq. (5)):

$\mathrm{x}(\mathrm{t}+1)=x(t) \frac{A x(t)}{x(t)^{T} A x(t)}$

where $x$ represents the strategy space of the underlying evolutionary dynamic, modeled as a probability distribution, indicating the propensity of each data point to belong to a cluster.

The clusters are extracted sequentially from the graph using a peeloff strategy to remove data points belonging to already extracted clusters, until there are no more objects to be clustered or other predefined criteria are satisfied.

The similarity function used to weight the graph $G$ is the cosine similarity. It takes as input the data representations of two objects (i.e. spectra here) $i$ and $j$ encoded in two feature vectors, $v_{i}$ and $v_{j}$ and is calculated as reported in Eq. (6):

$\cos \left(v_{i}, v_{j}\right)=1-\frac{v_{i} \cdot v_{j}}{\left\|v_{i}\right\|\left\|v_{j}\right\|}$

This measure restitutes the cosine of the angle between the two vectors and returns values ranging from -1 to 1 . High values indicate a high similarity.

This algorithm does not require knowing in advance the number of clusters to extract from the data set, a limitation of many partitional clustering algorithms, such as k-means [54] or minimum cut [55]. More importantly, this algorithm is able to identify groups of objects that have very similar characteristics. This second feature is particularly appealing and suited for the clustering of FORS data collected on Guggenheim textile collection, which contains a large number of fabric samples, some of them maybe dyed with similar colorants and/or subjected to similar degradation processes. We aimed at investigating both aspects of the investigated collection with this statistical approach.

In this study four spectral intervals were considered and compared (400-900 nm, 400-600 nm, 400-650 nm and 400-700 nm), while limiting the cluster number to 30 , since a further increase was observed to lower the discrimination capability, and generated clusters start to become very small. The residual data points, indicated as outliers, have different characteristics with respect to other objects, generally because of data noise or intrinsic spectral features. In the latter case, a further analysis of such objects would be interesting in order to better understand their peculiarities.

\section{Discussion of the Results}

\subsection{Macro-photography}

Macro images in diffuse light demonstrated to be particularly useful to study the structure and the conservation state of textile artworks: a selection of pictures both front and back sides of selected fabric fragments (a detailed list is reported in Table 2) are presented in Fig. 4, reporting interesting details observed on some samples. Fig. 4a refers to sample C1T6 and displays a thick weft (probably linen) and two fine silk warps - a gold yellow and a red one - forming the velvet and a lot of metallic threads, lamellae in particular, clearly distinguishable. Metal threads, their metals content and the different techniques employed to produce thin metallic lamellae, pliable enough for spinning round a silk fibers core, were already studied and described in literature

\section{Table 2}

List of the selected samples, their attributed date (were given) and type: were possible $\left({ }^{*}\right)$ the classification given by the school was reported, while for samples where it was not given a tentative identification is reported. ${ }^{*}$ indicates attribution and date given by D. Davanzo-Poli; in these cases new indications are added to the school ones.

\begin{tabular}{|c|c|c|}
\hline Sample name & Date (century) and provenience & Type \\
\hline C1T1a & XVIII & Embroidered fabric* \\
\hline C1T1b & XVIII & Fabric* \\
\hline C1T1c & XVIII & Fabric* \\
\hline C1T2a & XVI & Embossed velvet* \\
\hline $\mathrm{C} 1 \mathrm{~T} 2 \mathrm{~b}$ & XVI & Embossed velvet* \\
\hline C1T3 & XVI, Utrecht & Velvet* \\
\hline \multirow[t]{2}{*}{ C1T4 } & XVI & brocade* $^{*}$ \\
\hline & XVI-last quarter-Italy ${ }^{\#}$ & Gros liseré brocade ${ }^{\#}$ \\
\hline C1T5 & XVI-XVII, Italy ${ }^{\#}$ & Gros liseré lancé ${ }^{\#}$ \\
\hline \multirow[t]{2}{*}{ C1T6 } & $\mathrm{XV}$ & Velvet $^{\#}$ \\
\hline & XV-second half-, Italy ${ }^{\#}$ & \\
\hline C1T7a & XVIII & Brocades Louis XV* \\
\hline $\mathrm{C} 1 \mathrm{~T} 7 \mathrm{~b}$ & XVIII & Brocades Louis XV* \\
\hline C1T8 & XVIII & Fabric Louis XVI* \\
\hline \multirow[t]{2}{*}{ C1T9a } & XVIII & Velvet, Brocades* \\
\hline & XVIII-beginning-, France or Venice ${ }^{\#}$ & Lampas brocades" \\
\hline C1T9b & XVIII & Velvet, Brocades* \\
\hline C1T9c & XVIII & Velvet, Brocades* \\
\hline \multirow[t]{2}{*}{ C1T9d } & XVIII & Velvet, Brocades* \\
\hline & XVII-half- Italy & Damask lancé ${ }^{\#}$ \\
\hline \multirow[t]{2}{*}{ C1T9e } & XVIII & Velvet, Brocades* \\
\hline & XVII-half- Italy & Damask lancé \\
\hline $\mathrm{C} 2 \mathrm{~T} 1$ & / & Velvet \\
\hline $\mathrm{C} 2 \mathrm{~T} 2$ & XV-XVI century, Italy" & Velvet*\# \\
\hline C2T3 & XV-XVI, Italy ${ }^{\#}$ & Velvet \\
\hline $\mathrm{C} 2 \mathrm{~T} 4$ & / & Velvet \\
\hline C2T5 & / & Velvet \\
\hline C2T6 & / & Embroidery, Velvet \\
\hline $\mathrm{C} 2 \mathrm{~T} 7$ & XVI- second half-Italy & Velvet ${ }^{\#}$ \\
\hline $\mathrm{C} 2 \mathrm{~T} 8$ & / & Brocade \\
\hline С2Т9 & / & Satin \\
\hline C2T10 & XVII & Brocades Louis XIV* \\
\hline C3T1a & XVI end of, Italy ${ }^{\#}$ & Velvet $^{\#}$ \\
\hline C3T1b & XVI century & Velvet $^{\#}$ \\
\hline C3T2 & XVIII & Velvet Louis XV* \\
\hline C3T3 & XVIII & Fabric Louis XVI* \\
\hline C3T4 & XVI century & Velvet* \\
\hline C3T5 & / & Brocade \\
\hline C3T6 & XVI & Velvet* \\
\hline C3T7 & XVII-last quarter-Italy" & Damask brocades" \\
\hline C3T8 & / & Brocade \\
\hline С3Т9 & / & Embroidery \\
\hline С3Т10a & XVI & Velvet* \\
\hline C3T10b & XVI & Velvet* \\
\hline \multirow[t]{2}{*}{ C3T11a } & XVII & Brocades Louis XIV* \\
\hline & XVIII-third quarter-Italy & Taffetas liseré brocades ${ }^{\#}$ \\
\hline \multirow[t]{2}{*}{ C3T11b } & XVII & Brocades Louis XIV* \\
\hline & XVIII-third quarter-Italy ${ }^{\#}$ & Taffetas liseré brocades ${ }^{\#}$ \\
\hline \multirow[t]{2}{*}{ C3T11c } & XVII & Brocades Louis XIV* \\
\hline & XVIII-third quarter-Italy ${ }^{\#}$ & Taffetas liseré brocades ${ }^{\#}$ \\
\hline C3T12 & XVIII-last quarter-Italy ${ }^{\#}$ & Taffetas liseré ${ }^{\#}$ \\
\hline
\end{tabular}

[55,56]: Theophilus in the XII century [57] and Biringuccio in 1540 [58] explained that metal threads consisted in a wire rolled to a lamella and gilded on both sides; notwithstanding this in the XVI century ancient techniques such as the gilding of lamellae on only one side were still used.

Fig. 4b is referred to C3T10a sample, allows noticing the riant gilded metal treads, which is wound around a red silk yarn core. The metal dark color can be easily attributed to ongoing alteration, probably oxidative, phenomena: as known for every material, environmental conditions, both indoors and outdoors, have long been known to affect them [56].

The visual inspection of this sample, as of many others from the set, revealed also the diffuse presence of mildew testifying the poor conservation conditions of the collection, probably due to prolonged bad storage under unsuitable and uncontrolled temperature and humidity conditions. 


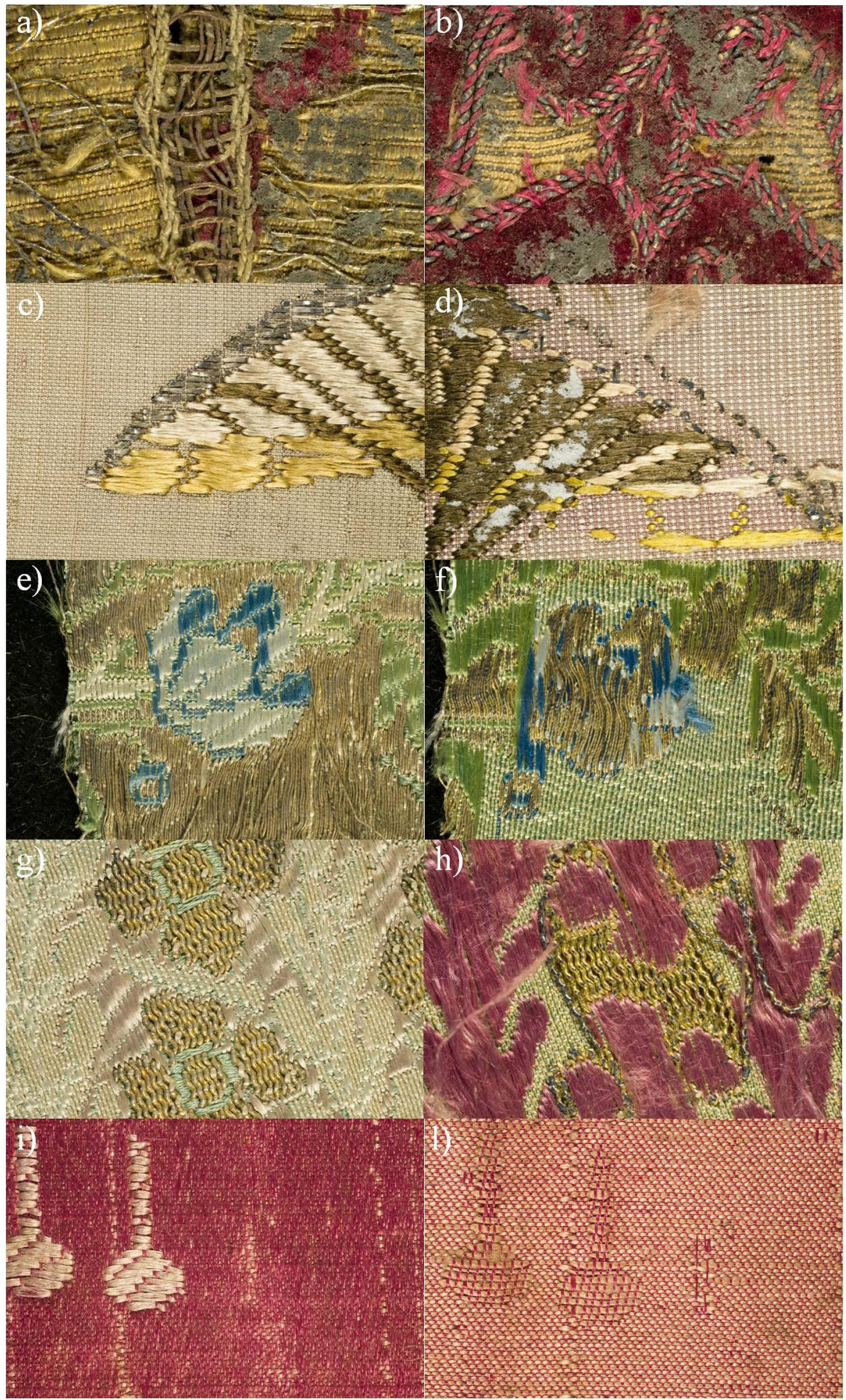

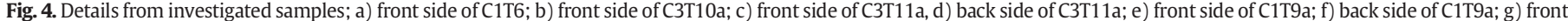
side of C1T9a; h) back side of C1T9a; i) front side of C1T1b; l) back side of C1T1b.

Fig. 4c and d show the front and back of the umbrella embroidery in C3T11a (which can be representative also of C3T11b and C3T11c samples); the discoloration of background fabric color occurred on the front side of this sample is evident from the comparison with the back side image, the last one clearly being brighter and pinker; as known natural colorants generally display a low color fastness, depending not only on the dye but also on the mordent and on the substrate [59-62]. Indigo, for example, is much more resistant on wool than on cotton, while the contrary is known for madder; many dyes exhibit higher light-fastness on a chromium-based mordent than on other mordents, while brazilwood, on the other hand, can be altered in all circumstances [60].

This effect resulted very evident also for C1T1a sample (Fig. 4e, f, g, $\mathrm{h}$ ), where a comparison between front and back sides of two different 
points allowed appreciating how the reddish purple embroidery looked very discolored on the front, while blue and light blue ones appeared instead quite stable to bleaching. Metal threads, from straight (Fig. 4e, f) and curly (Fig. 4g, h) gilded lamellae wounded on a yellow silk core, were present, some of them resulting extremely oxidized (especially on the back side), while others exhibiting no visible modifications.

Metal threads in form of lamellae are also visible on the C3T11a textile fragment, appearing darker on the back side when compared with the front one. Here, as in several other samples, residual paper glued to textiles surfaces was detected: it probably derived from the storage arrangement adopted for the entire collection in the last decades, since all pieces were then collected in a sort of album. Furthermore, also Guggenheim himself exposed many fragments in frames and gluing them on cardboards as described in Section 2.1.

When observing sample C1T1c (Fig. 4i, 1), small failures on the front side were noted, while the examination of its back side allowed understanding that they do not derive from fabric deterioration processes, but from production defects since both warp and weft threads result misplaced and not missing.

In general, all high resolution macro imaging analysis allowed distinguishing the linear shape of filaments, and permitting the identification of silk material as main material.

\subsection{Colorimetry}

Colorimetric data were obtained for each analyzed point when collecting FORS data. The L*a*b* coordinates were extracted and used to evaluate variations in color appearance: distribution of $\mathrm{a}^{*}$ and $\mathrm{b}^{*}$ values is reported in Fig. 5a, b for front and back sides, respectively. Red (also including the pink hues) and yellow points look less scattered on the back than on the front sides, while $\mathrm{a}^{*}$ and $\mathrm{b}^{*}$ values referred to other colors resulted more spread. This could be generally due to the preservation states of dyes on both sides; in particular, these two color

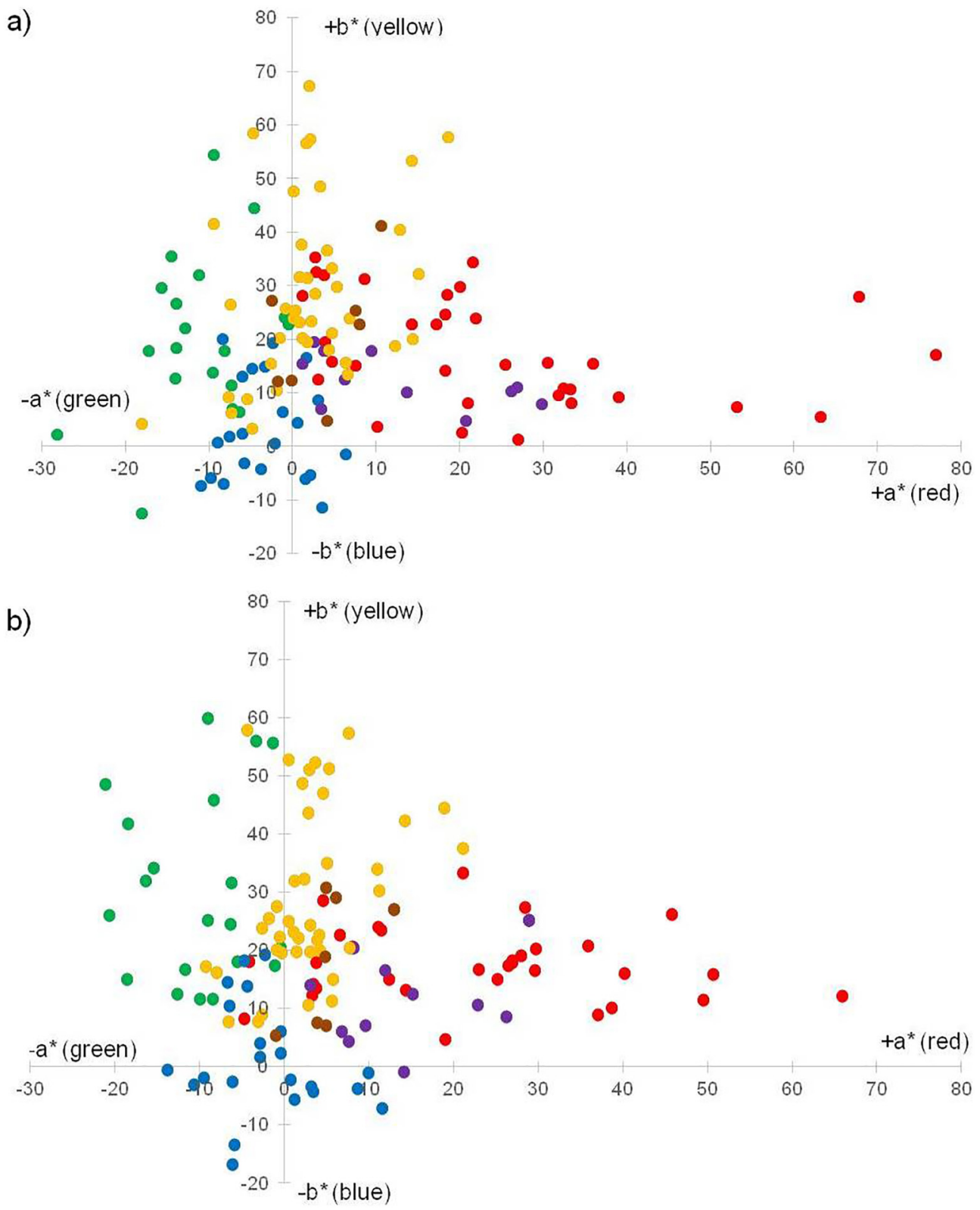

Fig. 5. Color parameters of analyzed samples projected on $a^{*} b^{*}$ plane of CIEL*a*b* color space: a) front sides; b) back sides. 
a)

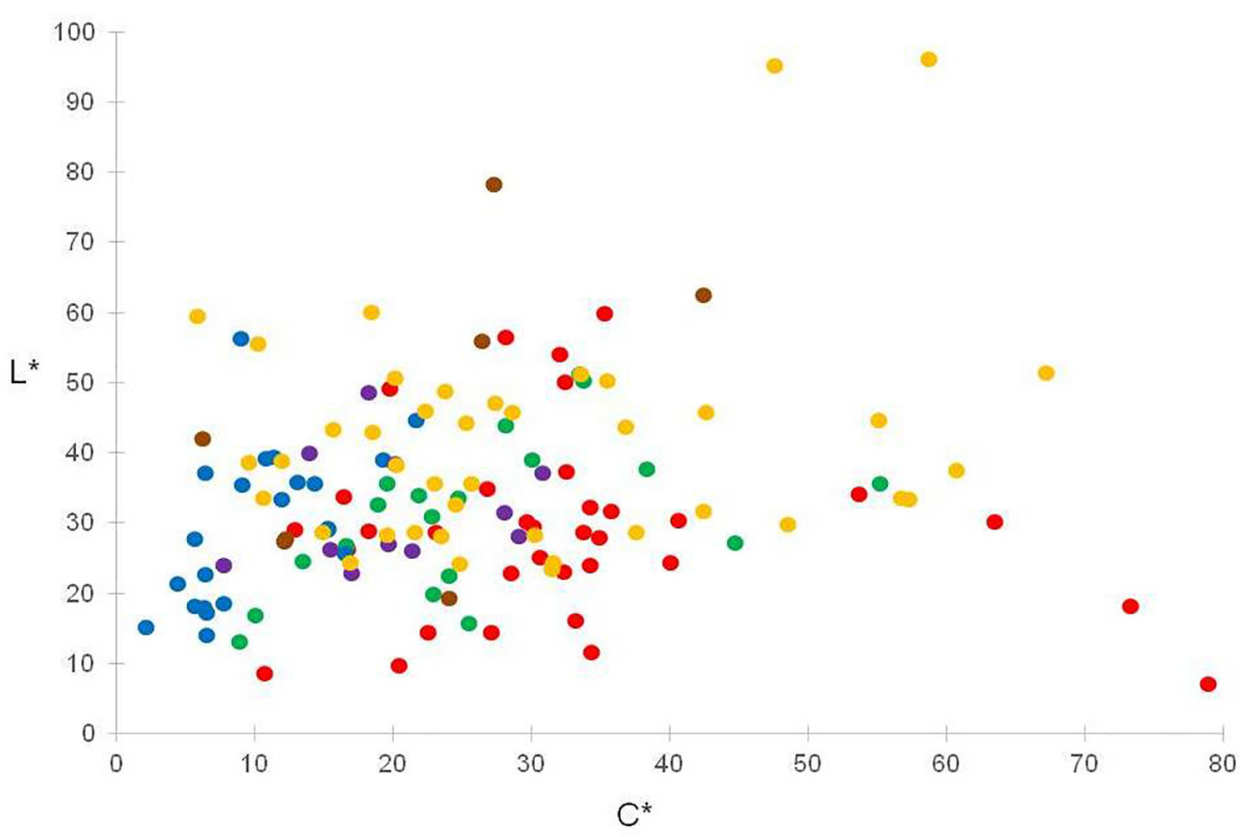

b)

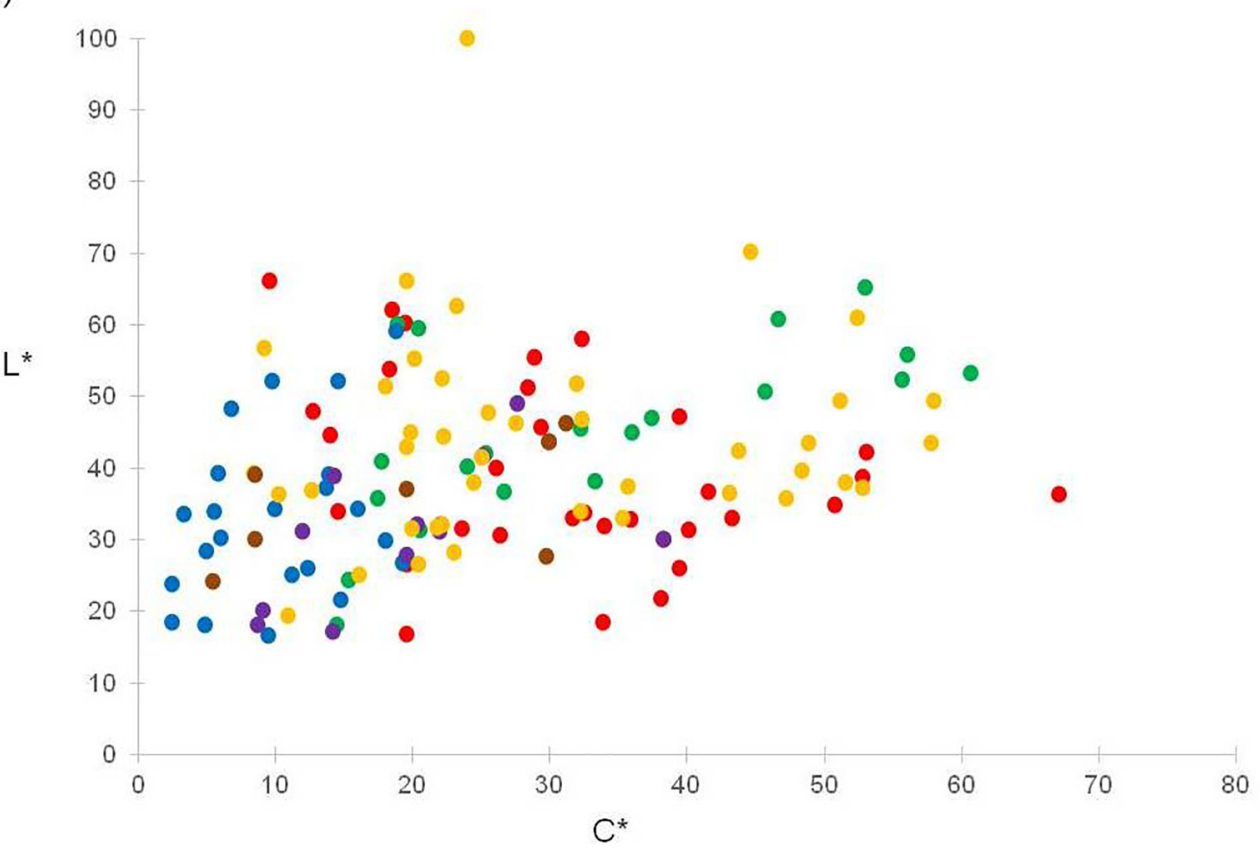

Fig. 6. Color parameters of analyzed samples projected on the $C^{*} L^{*}$ plane: a) front sides; b) back sides.

shades resulted better preserved on the back side than in corresponding front areas; a slightly different conclusion could be achieved by observing green areas, since this hue was usually obtained by mixing blue and yellow dyes. A closer distribution of green points on front sides could indicate that employed yellow colorants in the mixture (less fast than the blue ones) altered faster, shifting their corresponding coordinates along blue side of the $b^{*}$ axis.

Similarly, Fig. 6a, b show C* (see Eq. (1)), a measure of overall color saturation, and $\mathrm{L}^{*}$ trends on two sides of investigated samples, respectively: for both parameters recorded values on back sides gather within shorter intervals, while $\mathrm{L}^{*}$ data are globally shifted toward higher values, indicating a better conservation state of both dyes and silk threads. Green hues exhibited the same behavior observed in Fig. 5a, b.

The $\Delta \mathrm{E}_{76}{ }^{*}$ and $\Delta \mathrm{E}_{94}{ }^{*}$ values (Table 3 ) were determined to better evaluate color modifications between front and back sides: obtained values were generally much higher than the lowest color difference appreciable by human eye [29]. Because of high $\Delta \mathrm{E}^{*}$ values and their variability observed when many couples of points were analyzed for each hue, average values as well as their standard deviations, were considered instead, (Table 3). The last ones generally resulted quite large, probably because of different conservation state of threads in various fabric areas: this exhibited heterogeneity probably makes a comparison between colorimetric coordinates of both sides more reliable than the simpler evaluation of recorded $\Delta \mathrm{E}^{*}$ values. The main advantage in considering differences between single coordinates allows identifying parameters displaying most relevant variations, especially when just noticeable differences between front and back sides exist.

In addition, when corrections were applied according to the 1994 formula obtained values were generally lower and less variable that those obtained with the traditional $\Delta \mathrm{E}_{76}{ }^{*}$ equation (Table 3). The difference is not always remarkable but consistent with peculiar aspect of investigated materials, even if no defined trends could be observed. 
Table 3

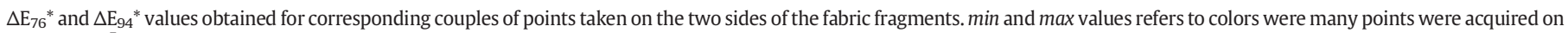
each side. $\Delta \overline{\mathrm{E}}^{*}$ is the color difference average value and $\sigma$ is the standard deviation.

\begin{tabular}{|c|c|c|c|c|c|c|c|}
\hline Sample & Color & $\Delta \mathrm{E}_{76}{ }^{*} \min / \Delta \mathrm{E}_{76}{ }^{*} \max$ & $\Delta \overline{\mathrm{E}}_{76}^{*}$ & $\sigma_{76}$ & $\Delta \mathrm{E}_{94}{ }^{*} \min / \Delta \mathrm{E}_{94}{ }^{*} \max$ & $\Delta \overline{\mathrm{E}}_{94}^{*}$ & $\sigma_{94}$ \\
\hline \multirow[t]{2}{*}{ C1T1a } & Pink & 37.2 & 37.2 & / & 36.8 & 36.8 & \\
\hline & Green & $39.4-65.3$ & 52.4 & 18.3 & $36.8-34.3$ & 35.6 & 1.8 \\
\hline \multirow[t]{2}{*}{ C1T1b } & Pink & $14.7-28.9$ & 20.6 & 7.4 & $11.8-27.9$ & 18.6 & 8.4 \\
\hline & Brown & 37.9 & 37.9 & / & 23.6 & 23.6 & / \\
\hline \multirow[t]{2}{*}{ C1T1c } & Red & 14.6 & 14.6 & / & 12.5 & 12.5 & / \\
\hline & Yellow & 9.0 & 9.0 & / & 4.5 & 4.5 & / \\
\hline \multirow[t]{2}{*}{$\mathrm{C} 1 \mathrm{~T} 2 \mathrm{a}$} & Red & 35.8 & 35.8 & i & 29.6 & 29.6 & / \\
\hline & Yellow & 28.1 & 28.1 & 1 & 14.8 & 14.8 & / \\
\hline $\mathrm{C} 1 \mathrm{~T} 2 \mathrm{~b}$ & Gold & $10.1-33.1$ & 21.7 & 8.0 & $10.2-24.8$ & 18.1 & 7.4 \\
\hline C1T3 & Green & $13.4-32.1$ & 22.8 & 13.2 & $14.5-18.5$ & 16.5 & 2.9 \\
\hline \multirow[t]{2}{*}{ C1T4 } & Blue & $18.4-28.7$ & 23.6 & 7.3 & $14.8-16.9$ & 15.8 & 1.4 \\
\hline & Yellow & $7.8-32.5$ & 20.2 & 17.5 & $4.9-31.0$ & 17.9 & 18.5 \\
\hline \multirow[t]{2}{*}{ C1T5 } & Red & 8.4 & 8.4 & / & 10.1 & 10.1 & \\
\hline & Golden & $21.3-39.8$ & 30.6 & 13.1 & $20.8-21.9$ & 21.4 & 0.8 \\
\hline C1T6 & Red & 5.5 & 5.5 & / & 5.4 & 5.4 & / \\
\hline \multirow[t]{3}{*}{ C1T7a } & Red & 13.2 & 13.2 & / & 9.2 & 9.2 & / \\
\hline & Green & 9.4 & 9.4 & / & 5.1 & 5.1 & / \\
\hline & Yellow & $29-29.3$ & 29.2 & 0.2 & $25.6-30.7$ & 28.1 & 3.6 \\
\hline C1T7b & Green & 6.9 & 6.9 & / & 5.7 & 5.7 & / \\
\hline C1T8 & Yellow & 3.7 & 3.7 & 1 & 2.7 & 2.7 & 1 \\
\hline \multirow[t]{4}{*}{ C1T9a } & Red & $19.8-33.1$ & 31.0 & 8.8 & $19.6-21.3$ & 20.3 & 0.8 \\
\hline & Green & $27.3-65.6$ & 52.3 & 27.0 & $19.7-49.1$ & 34.4 & 21.6 \\
\hline & Blue & $14.3-22$ & 36.6 & 5.4 & $8.4-20.3$ & 14.4 & 8.4 \\
\hline & Purple & $12.6-14.3$ & 19.9 & 1.2 & $6.7-15.9$ & 11.3 & 6.5 \\
\hline C1T9b & Red & $22.4-32.9$ & 27.6 & 7.5 & $11.7-32.3$ & 22.0 & 14.6 \\
\hline & Green & $6.8-51.5$ & 29.2 & 31.6 & $8.1-50.0$ & 29.0 & 29.7 \\
\hline & Purple & $15-16.8$ & 15.9 & 1.3 & $14.3-17.8$ & 16.0 & 2.5 \\
\hline & Yellow & 11.9 & 11.9 & I & 11.2 & 11.2 & 1 \\
\hline & Brown & 12.2 & 12.2 & / & 6.6 & 6.6 & / \\
\hline С1T9c & Green & 43.3 & 43.3 & / & 42.3 & 42.3 & / \\
\hline & Blue & 23.1 & 23.1 & 1 & 22.7 & 22.7 & 1 \\
\hline & Yellow & $20.9-52$ & 36.5 & 22.0 & $23.7-51.3$ & 37.5 & 19.5 \\
\hline C1T9d & Green & 45.8 & 45.8 & / & 45.9 & 45.9 & / \\
\hline & Yellow & 26.4 & 26.4 & 1 & 24.6 & 24.6 & 1 \\
\hline c1T9e & Red & $7-25.6$ & 18.1 & 8.0 & $8.0-18.1$ & 14.8 & 4.6 \\
\hline $\mathrm{C} 2 \mathrm{~T} 1$ & Purple/red & $4.74-20.29$ & 13.7 & 8.0 & $4.1-20.4$ & 13.3 & 8.3 \\
\hline $\mathrm{C} 2 \mathrm{~T} 2$ & Red & $33.8-83.3$ & 51.5 & 27.6 & $20.0-64.7$ & 36.3 & 24.6 \\
\hline $\mathrm{C} 2 \mathrm{~T} 3$ & Dark green & 42.7 & 42.7 & l & 38.0 & 38.0 & / \\
\hline & Yellow & 40.7 & 40.7 & / & 28.4 & 28.4 & / \\
\hline & Brown & 11.6 & 11.6 & / & 9.3 & 9.3 & / \\
\hline C2T4 & Brown & $12.32-15.19$ & 51.5 & 27.6 & $8.5-9.8$ & 9.1 & 0.9 \\
\hline C2T5 & Blue & $15.2-36.9$ & 26.0 & 15.3 & $12.1-22.0$ & 17.0 & 7.0 \\
\hline C2T6 & Yellow/green & 3.8 & 3.8 & / & 3.1 & 3.1 & / \\
\hline & Blue & $19.2-25.4$ & 22.4 & 4.4 & $12.6-12.8$ & 12.7 & 0.2 \\
\hline $\mathrm{C} 2 \mathrm{T7}$ & Red & 14.3 & 14.3 & / & 11.3 & 11.3 & / \\
\hline С2T8 & Red & $7.9-29.5$ & 18.7 & 15.3 & $7.8-20.9$ & 14.3 & 9.3 \\
\hline & Yellow & 8.8 & 8.8 & / & 7.0 & 7.0 & / \\
\hline С2T9 & Red & 27.6 & 27.6 & / & 20.3 & 20.3 & / \\
\hline & Yellow & 29.5 & 29.5 & / & 19.3 & 19.3 & / \\
\hline C2T10 & Green & 14.1 & 14.1 & / & 10.8 & 10.8 & 1 \\
\hline & Brown & 20.1 & 20.1 & 1 & 13.3 & 13.3 & / \\
\hline C3T1a & Blue & $9.6-28.7$ & 16.2 & 10.8 & $7.2-16.1$ & 10.4 & 4.9 \\
\hline & Yellow & $4.5-32.9$ & 15.3 & 15.3 & $3.3-19.9$ & 10.0 & 8.8 \\
\hline C3T1b & Green & $16.4-22.2$ & 18.8 & 3.0 & $9.0-15.2$ & 11.6 & 3.3 \\
\hline & Yellow & $13.1-20.8$ & 16.8 & 3.9 & $10.3-14.0$ & 11.6 & 2.1 \\
\hline С3Т2 & Blue & $21.1-29.9$ & 26.8 & 4.9 & $10.6-17.1$ & 14.1 & 3.2 \\
\hline С3Т3 & Yellow & $57.2-62.1$ & 58.9 & 2.8 & $31.6-42.1$ & 36.8 & 5.3 \\
\hline C3T4 & Black & $10.7-23.6$ & 17.1 & 9.1 & $6.5-15.2$ & 10.8 & 6.1 \\
\hline & Yellow & 19.8 & 19.8 & i & 10.2 & 10.2 & / \\
\hline С3Т5 & Blue & $14.2-18.6$ & 16.4 & 3.1 & $8.4-18.8$ & 13.6 & 7.3 \\
\hline & Yellow & $9.8-20.1$ & 15.8 & 5.3 & $6.0-20.9$ & 15.1 & 8.0 \\
\hline С3T6 & Green & $9-29.1$ & 19.0 & 14.2 & $6.8-19.1$ & 12.9 & 8.7 \\
\hline C3T7 & Blue & 26.7 & 26.7 & / & 14.2 & 14.2 & / \\
\hline С 3 Т 8 & Golden & $4.7-16.1$ & 9.7 & 5.5 & $3.0-12.4$ & 7.5 & 3.8 \\
\hline С3Т9 & Blue & $4.7-10.4$ & 7.7 & 3.0 & $4.2-6.3$ & 5.4 & 0.9 \\
\hline & Pink & $9.6-18.2$ & 13.0 & 3.8 & $10.2-12.4$ & 11.4 & 1.1 \\
\hline & Purple & $17.5-24.2$ & 20.9 & 4.7 & $12.8-18.3$ & 15.5 & 3.8 \\
\hline & Yellow & $17.2-43.1$ & 30.0 & 18.3 & $8.2-34.0$ & 26.1 & 11.2 \\
\hline C3T10a & Red & 23.0 & 23.0 & / & 21.8 & 21.8 & / \\
\hline & Yellow & 22.9 & 22.9 & / & 17.9 & 17.9 & 1 \\
\hline C3T10b & Yellow & 14.2 & 14.2 & / & 11.6 & 11.6 & 1 \\
\hline C3T11a & Red & 25.2 & 25.2 & / & 13.8 & 13.8 & / \\
\hline & Purple & 21.3 & 21.3 & / & 14.9 & 14.9 & / \\
\hline C3T11b & Red & 23.5 & 23.5 & / & 15.8 & 15.8 & / \\
\hline
\end{tabular}


Table 3 (continued)

\begin{tabular}{|c|c|c|c|c|c|c|c|}
\hline Sample & Color & $\Delta \mathrm{E}_{76}{ }^{*} \min / \Delta \mathrm{E}_{76}{ }^{*} \max$ & $\Delta \overline{\mathrm{E}}_{76}{ }^{*}$ & $\sigma_{76}$ & $\Delta \mathrm{E}_{94}{ }^{*} \min / \Delta \mathrm{E}_{94}{ }^{*} \max$ & $\Delta \overline{\mathrm{E}}_{94}{ }^{*}$ & $\sigma_{94}$ \\
\hline \multirow[t]{4}{*}{ C3T11c } & Red & 8.9 & 8.9 & / & 5.7 & 5.7 & / \\
\hline & Green & 44.6 & 44.6 & l & 31.7 & 31.7 & / \\
\hline & Purple & 7.5 & 7.5 & / & 7.1 & 7.1 & / \\
\hline & Brown & 20.1 & 20.1 & / & 11.3 & 11.3 & / \\
\hline
\end{tabular}

\subsection{Vis-reflectance Spectroscopy}

The analysis of reflectance spectra collected in the visible light interval (350-750 nm) can be quite difficult when approaching the study of natural dyes, especially on historical textiles that underwent various and mainly unknown ageing processes. Ancient fabrics very often display, as in this case, the simultaneous use of threads of different colors in their structure, as well as for realizing embroideries, often leading to superimposed spectral features deriving from very close fibers. This often adds to the widespread use of colorants generated by mixtures, principally for obtaining green and purple hues.

The discussion of spectral data has been divided according to a hue classification. The whole spectra set exhibited quite low intensities, which could be attributed to ageing and related color fading processes, according to Clementi et al. [7], or in other cases to the quite high concentration of colorants, as reported by Gulmini et al. [11].

\subsubsection{Blue Hues}

In all analyzed samples blue hues could be referred to woad and indigo: according to literature $[5,11,63-65]$, the main features of indigotin reflectance spectrum are a maximum between 430 and $480 \mathrm{~nm}$, which shifts toward shorter wavelengths for lighter colors [11], and an inflection point between 690 and $730 \mathrm{~nm}$. The maximum absorbance lies at about $660 \mathrm{~nm}$ [5], which corresponds to a reflectance minimum.

Reflectance spectra shown in Fig. 7-left display features referable to those of indigotin already reported by various authors $[5,10,11,64,66]$, so indicating a good conservation state of this colorant: the main reflectance maximum was recorded between 446 and $454 \mathrm{~nm}$, with an absorption band varying between 650 and $660 \mathrm{~nm}$ (Table 4) and an inflection point centered between 707 and $723 \mathrm{~nm}$, leading to a sharp reflectance increase in the infrared region [11]. In addition, other less intense spectral features are distinguishable, in particular three reflectance maxima at about 504, 560-570 and $617 \mathrm{~nm}$, and three minima (corresponding to absorption maxima) at 477, 545 and $600 \mathrm{~nm}$, respectively. Spectra collected on these historical samples not resemble the reflectance spectrum acquired on a commercial powder of indigo, which is, conversely, very similar to that proposed by Gulmini et al. [11] for a very dark sample.

As known from literature, the main indigotin absorption band is due to a strong $\pi \rightarrow \pi^{*}$ transition (Table 4 ) centered at about $540 \mathrm{~nm}$ when indigotin is in the vapor phase, and undergoing bathochromic shifts when in solution and solid phase because of the formation of hydrogen-bond aggregates, mostly dimers $[11,67,68]$.

Several samples displaying light blue or grayish areas exhibited reflectance spectra as those reported in Fig. 7-right: as a matter of fact, these spectral profiles are comparable with data published for pale blue [60] or green [11] colors. This is not surprising since green hues were usually obtained by consecutive dyeing of textiles with blue and yellow colorants, being indigo the first one, whose absorption and inflection points are generally maintained also in obtained mixtures. As a consequence, the spectral changes associated to different shades could be interpreted as due to the colorant dilution [64], or as induced by dye alteration processes. Indigotin is already reported to be particularly lightfast [69] and highly sensitive to ozone [59,70,71], leading to a bluish-grey appearance and to modifications of its spectral profile. This induces a reflectance maximum shift toward longer wavelengths (closer to or even overlapping the green spectral range) associated with no relevant modifications of absorption maximum. The same behavior was observed in the investigated fragments: exemplificative spectra reported in Fig. 7-right show the disappearance of main reflectance maximum and variations in relative intensities of longer wavelength features, until their complete smoothing; the absorbance maximum was found to lie between 650 and $655 \mathrm{~nm}$.

\subsubsection{Red and Pink Hues}

The main traditional coloring agents for red dyes were alizarin, purpurin and carminic acid or kermensic acid, extracted from madder,
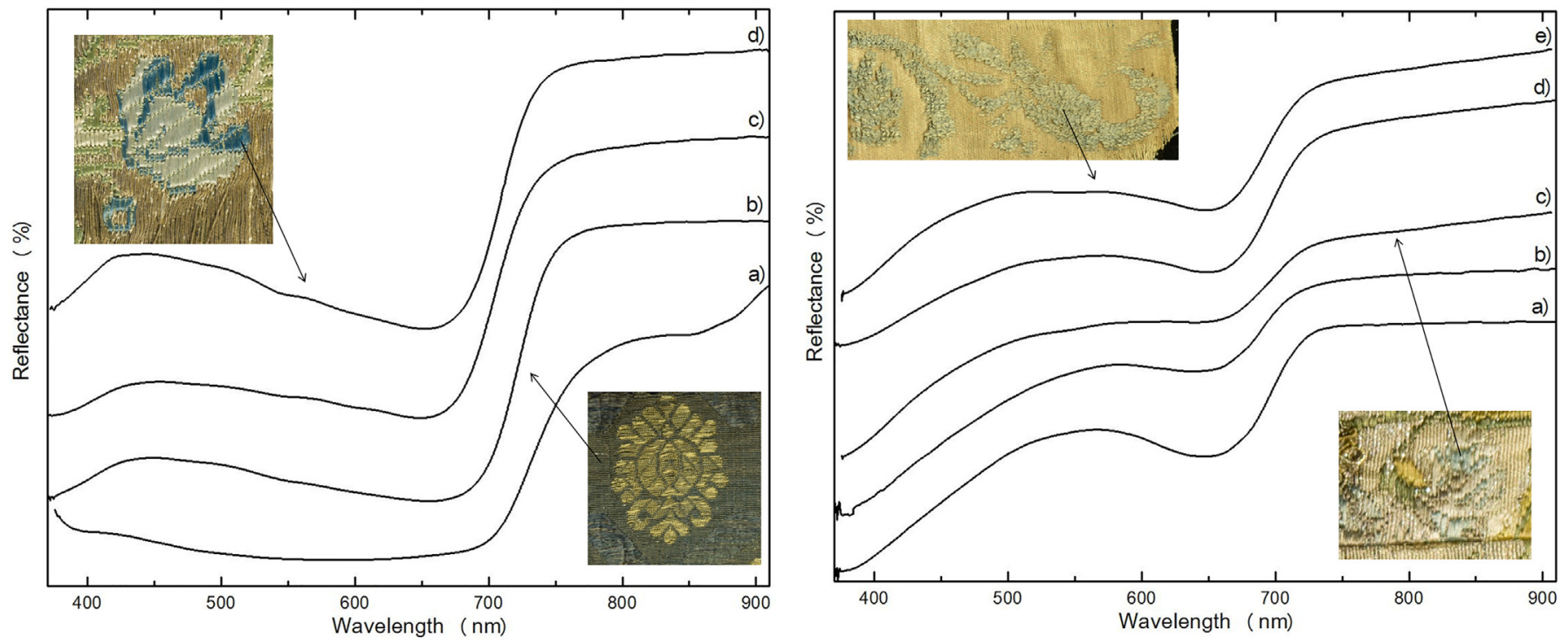

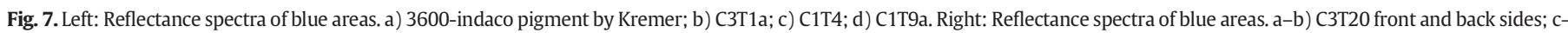
d) C1T7b front and back; d-e) C2T6 front and back side. 
Table 4

Principal absorption positions and attributions of the main identified dyes.

\begin{tabular}{llll}
\hline Dye & Wavelegth $(\mathrm{nm})$ & Attribution & Reference \\
\hline Indigotin & $650-660 \mathrm{a}$ & $\pi \rightarrow \pi^{*}$ & 11 \\
Cochineal & $520-535$ & $\mathrm{n} \rightarrow \pi^{*}$ transitions of carbonyl groups & $75-78$ \\
& $550-575$ & & \\
Madder & $505-515$ & & 11 \\
& $540-550$ & & $11,80,81$ \\
Brazilein & $445-450$ & Complex brazilein-mordant & \\
Flavonoids & $320-380$ & $\pi \rightarrow \pi^{*}$ transition of cinnamoyl group & 11,80 \\
\hline
\end{tabular}

cochineal and its congener kermes, respectively [72], all such substances exhibit a strong dependency of their absorption maxima from the chemical neighborhood of the hydroxyl groups on the anthraquinone unit. The use of these colorants was historically assessed for various purposes (such as painting, inks, textile dyeing, etc.) and it is known that kermes, an insect native to southern Europe, was widely employed until the late XVI century, when cochineal, able to provide a ten times more efficient dye in terms of coloring power, started to be imported from Mexico and to completely replace it [72-74].

Reflectance spectra recorded from these dyes normally display a quite similar shape, slightly differing only in the position of their absorbance maxima: cochineal maxima are approximately located between 520-535 and 550-575 nm, while madder absorbs at about 505-515 and 540-550 nm (Table 4) [5,10,11,75]. Moreover, cochineal reflectance spectra can exhibit a reflectance band in the blue region, between 415 and $435 \mathrm{~nm}$, which is barely appreciable for madder, between 425 and $450 \mathrm{~nm}$ [11]. All the cited absorption features seem not to be modified by mordants, while their inflection point, located in the red portion of the visible spectrum, at approx. $600 \mathrm{~nm}$, can be instead easily influenced by them, thus affecting their spectrum and consequently the resulting color [11].

The absorption behavior in the visible region of these anthraquinone-based dyes is principally due to $n \rightarrow \pi^{*}$ transitions of carbonyl groups in the molecules (Table 4) [75-78].

Because of the similarity of anthraquinones reflectance profiles, it can be quite difficult discriminating madder from cochineal [5], especially when examining very dark samples, since color saturation can also affect their spectra, usually displaying quite low intensity profiles below $570 \mathrm{~nm}[11,78]$.
In examined samples red and pink colors were found in both woven fabric and embroideries, often realized with red-orange or deep pink threads, mostly turned into beige or light pink hues on front side.

Fig. 8-left reports some exemplificative spectra typically attributable to anthraquinone based dyestuffs in a good conservation state, as confirmed by the good readability of features; the greatest difference concerns the position of main reflectance maxima, ranging between 450 (Fig. 8left-e) and $474 \mathrm{~nm}$ (Fig. 8left-d), resulting compatible with values reported for madder and related differences attributable to the use of different mordants [11,12]. Their absorption maxima showed fewer variables, being always located at 492, 523 and $572 \mathrm{~nm}$ and well matching values already available for cochineal. In particular Fig. 8right-b looks very similar to the spectrum reported by Gulmini et al. [11] for cochineal post-mordanted with iron(II), while Fig. 8left-a refers to a very dark sample that could be compared with a colorant mordanted with alum prepared by the same authors [11].

In few other cases (mostly on embroideries) reflectance spectra revealed the application of brazilwood [11,12] (Fig. 8right-c), another quite diffuse red dye, considered of lower quality than madder or cochineal because of its lower stability with time.

Its spectral profile is generally less structured than the anthraquinones one and is characterized by a main reflectance band in the violet-blue region centered at about $460 \mathrm{~nm}$ that can be split in two components, so exhibiting a less intense reflectance maximum at lower wavelength due to a weak (not always present) absorption band between 445 and $450 \mathrm{~nm}[11,12,75]$. Other typical features of brazilwood are an absorption band between 520 and $560 \mathrm{~nm}$ and an inflection point falling between 585 and $600 \mathrm{~nm}[11,72]$. These last two features can vary greatly depending on the mordanting ion, while the weak absorption at about $445-450 \mathrm{~nm}$ is maintained (Table 4). This feature is probably due to the formation of complexes between brazilein, the omoisoflavonoid contained in the brazilwood extract, and the metallic ion used as mordant (Table 4) [11].

In few other cases tannins were mixed with a yellow colorant, usually a flavonoid, and/or with a red dyestuff in order to obtain a light brown-orange hue, as exhibited by floral embroideries in C1T1b, which turned into a pale pinkish hue on the front side.

Spectra reported in Fig. 8-right well fit profiles reported by literature $[11,74,77]$, showing reflectance maxima centered at approx. $463 \mathrm{~nm}$, absorptions at approx. $510 \mathrm{~nm}$ and inflection points between 569 and $600 \mathrm{~nm}$, at lower wavelengths with respect to anthraquinones; only
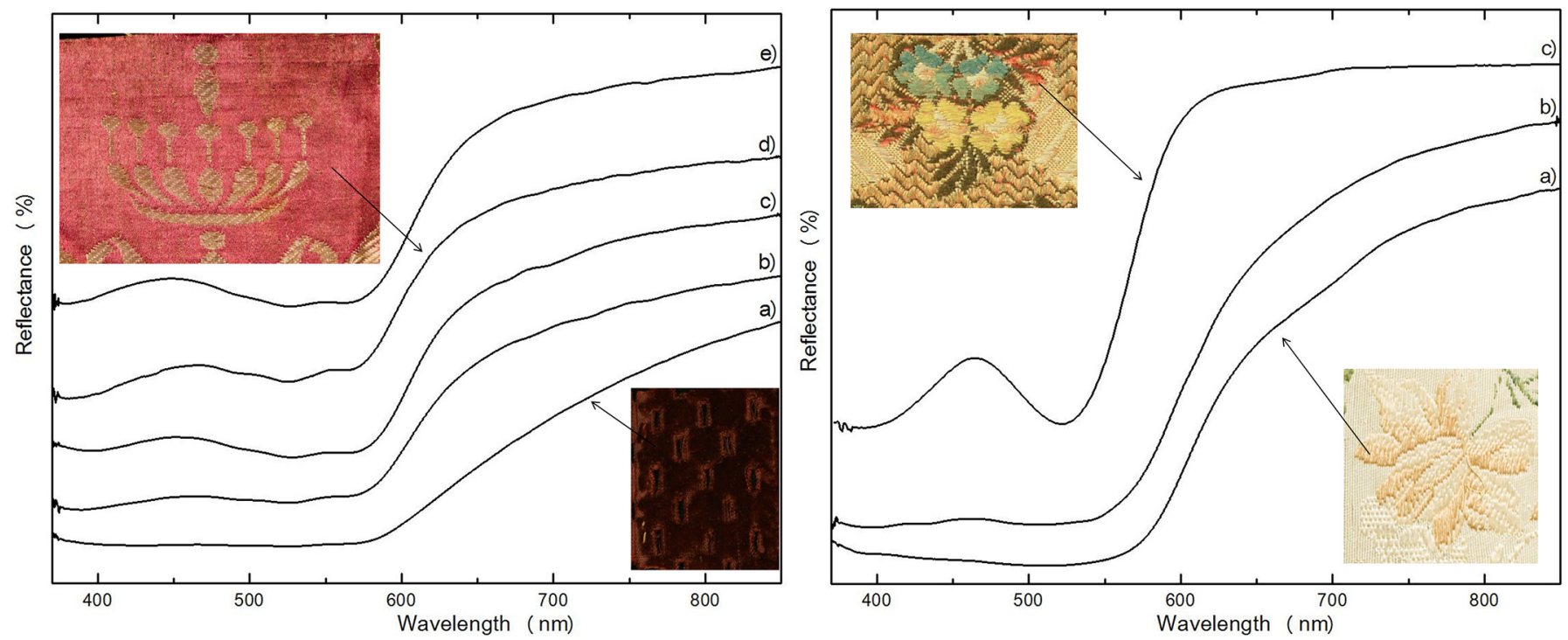

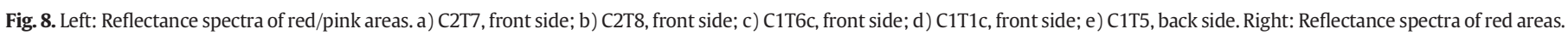
a) C1T1b, front side; b) C1T9b, back side; c) C3T12, front side. 
spectrum 8 left-c did not exhibit the first additional reflectance maximum [76].

\subsubsection{Yellow and Brown Hues}

Yellow colors could be traditionally obtained by means of several dyestuffs, about $90 \%$ of them being flavonoids, since many natural sources are easily available worldwide. All of them usually contain mixtures of coloring compounds, the most common being luteolin and apigenin for weld, fisetin and myricetin for young fustic, and morin for old fustic [79].

From a spectral point of view, the main characteristic of yellow dyes is an absorption between 320 and $380 \mathrm{~nm}$ (referred to as band I), due to the $\pi \rightarrow \pi^{*}$ transition of cinnamoyl group in the flavonoid structure (Table 4) [11,80,81], which can undergo a bathochromic shift (up to $400-450 \mathrm{~nm}$ ) in presence of metallic ions, due to mordants and/or to metallic threads in the fabric [11]. Inaccurate conservation conditions of investigated collection (exposed to the high relative humidity of Venice lagoon environment) may have led to alteration phenomena on these metallic parts and consequently to dissolution and diffusion processes.

The only spectral features exhibited by most common flavonoid dyes, such as fustic or weld, are the strong absorptions below $450 \mathrm{~nm}$ and an inflection point at around $490 \mathrm{~nm}[9,11,16]$. These compounds can often exhibit large variations in their spectral shapes, even on the same substrate and with similar dyeing procedures, that usually concern the steep increase of reflectance in the red region, sometimes associated to the presence of two different inflection points; in some cases their absorption maximum can also vary or even be absent [11]. As a consequence, FORS cannot be considered an adequate analytical technique to correctly discriminate yellow dyestuffs but should be coupled to more diagnostic analytical methods, such as GC-MS or HPLC-MS.

As concerning collected spectra, very different situations were observed, sometimes also on the same sample, as reported in Fig. 9-left, whose shown spectra cover the entire range of variants reported by literature $[9,11]$ and it was hypothesized that in the examined samples, the observed bathochromic shift would be due mainly to the presence of metallic threads.

Several samples exhibited also brown areas whose reflectance spectra often corresponded to those exhibited by tannins [5,9], a class of polyphenols that were used both as dyes or as mordants, and whose stability, especially toward photo-oxidative reactions, usually render colors particularly washing and lightfast [82,83], so affecting the ageing processes of parchment and textiles. Brown areas in examined samples (Fig. 9-right) are generally in form of embroideries or velvets and their colors are generally well preserved, apart from sample C3T4 (Fig. 9right-a), where the dark brown velvet resulted widely detached and threads look very fragile as a consequence of their deterioration.

More rarely, brown hues were historically obtained also by means of tannins mixed with flavonoid and/or red dyestuff, as already indicated for orange hues, or mordanting flavonoids with metal salts such as $\mathrm{FeSO}_{4}$ [13], i.e. in sample C2T3.

\subsubsection{Green Hues}

As anticipated, green hues were obtained by successive baths of blue and yellow dyes, respectively, generally applying indigotin as the blue one $[84,85]$. As a general rule, the presence of colorant mixtures lowers FORS diagnostic potential in their identification, since reflectance features of each dye could be barely detected or completely hidden [5]. Indigotin was also employed to obtain purple mixtures (see below), and in both cases its principal features are recognizable, while the yellow ones result instead quite hard to be identified [9].

Green hues are, in their numerous shades, the most present colors among selected samples; collected spectra (Fig. 10-left) displayed the typical shape of green colorants, whose yellow components cannot be identified but the presence of flavonoids can be supposed $[9,11]$. In darker hues, indigotin features resulted to dominate recorded spectra as in Fig. 10left-a. Some of studied textile fragments allowed collecting slightly different spectra, more structured below $670 \mathrm{~nm}$ (Fig. 10right): turmeric was hypothesized as the main yellow component of green hues, since identified features were consistent with those reported by Gulmini et al. [11] for this blend. The use of this colorant, containing polyenes as curcumin I, II and III [79] was quite common in colorant mixtures and slight differences observed in acquired spectra, such as first reflectance maximum shifting from 511 to $525 \mathrm{~nm}$ and a second one flowing between 566 and $573 \mathrm{~nm}$, could be related to different conservation conditions; the absorption (spectral minimum) was exhibited within 542 and $549 \mathrm{~nm}$ in all examined areas. A third FORS profile, recorded on sample C2T4 (Fig. 10right-e) and exhibiting a reflectance band below $450 \mathrm{~nm}$ and a barely visible absorption around $475 \mathrm{~nm}$, let to hypothesize that saffron could be the yellow dyestuff applied to this fabric to obtain the final green hue [11].
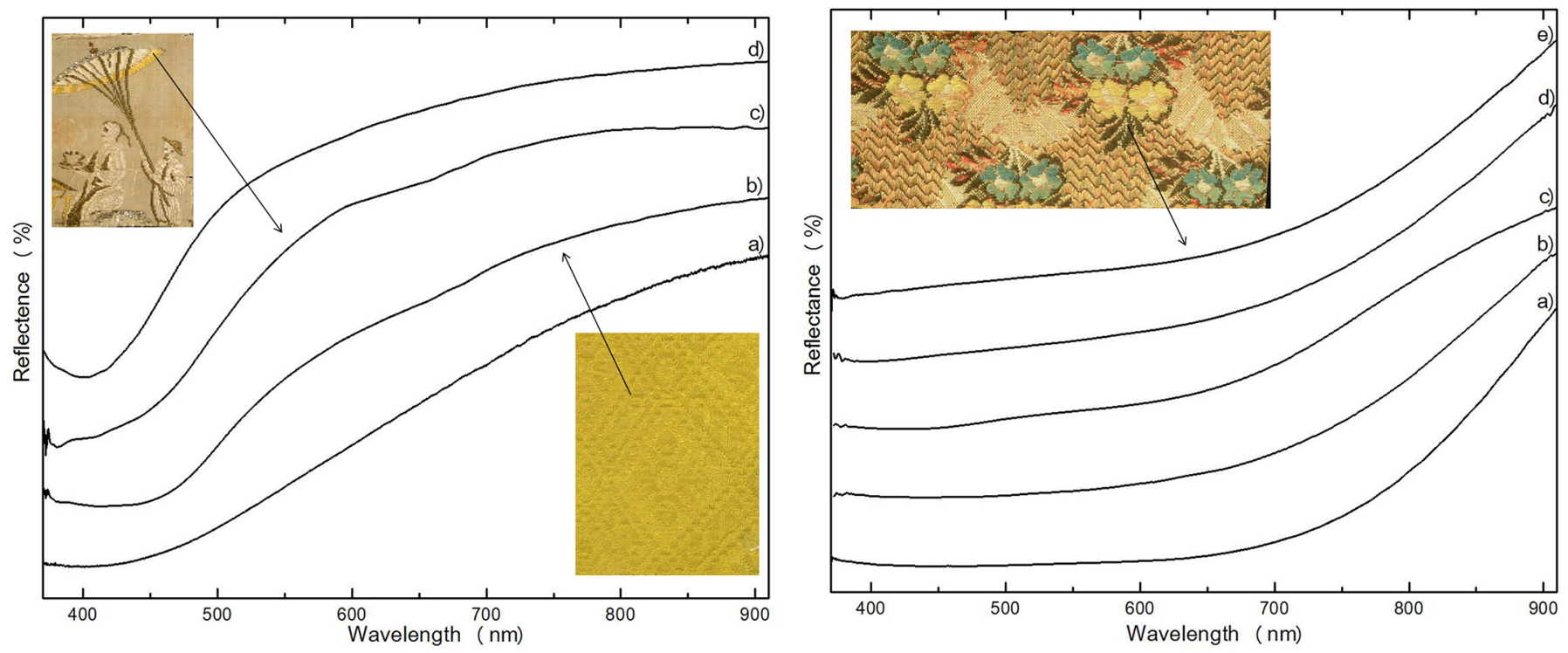

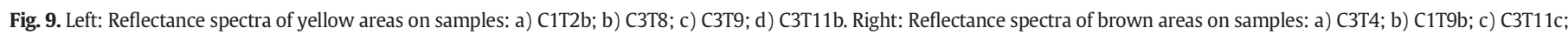
d) C2T10; e) C3T12. 

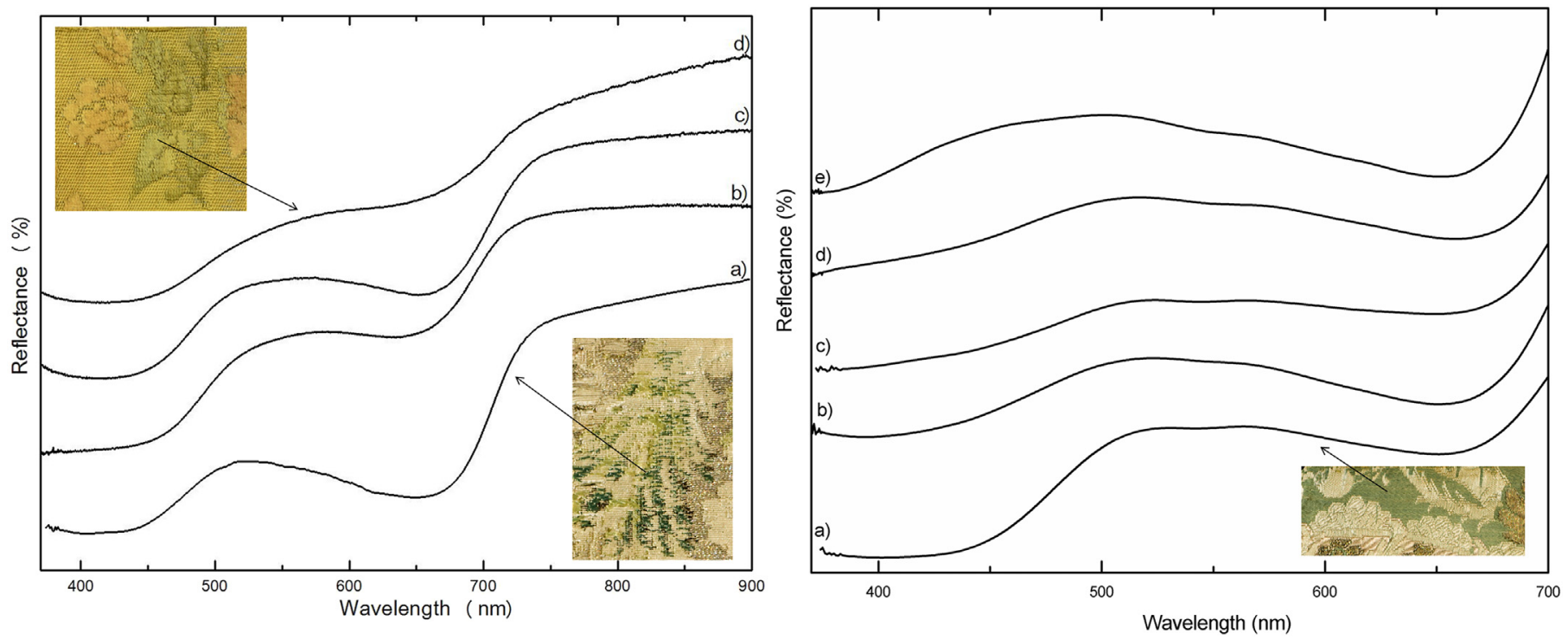

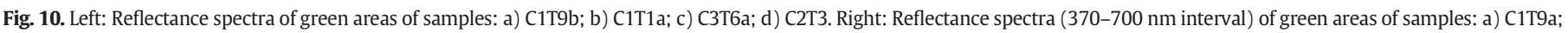
b) C3T6b; c) C1T1b; d) C1T3; e) C2T4.

\subsubsection{Purple Hues}

When indigotin is mixed with a red colorant, a purple hue can be obtained. Purple dyes as Tyrian purple, used until the XV century [61], or orcein, used as its cheaper alternative [7,79], were also known. The use of mixtures was much more common and either anthraquinones or omoisoflavonoid were utilized. The presence of cochineal is easier to be discerned by FORS, while the absorption of madder can result more difficult, being sometimes undetectable [11]. In addition, it is known that anthraquinones can exhibit purple hues also when treated with chromium salts, a technique introduced since 1796 [17].
Many of investigated fabrics exhibited purple hues: an interesting case study is represented by sample C1T4, appearing blue on the front side and purple on the back one. Measurements performed on several areas of the front side, differing in their manufacture, exhibited different results: in the opaque areas reflectance spectra well matched that of indigotin (Fig. 11a), while the brighter ones they indicated that a purple color was applied (Fig. 11b). The mixture seems to have been obtained using cochineal as red component [11] and indigo as blue one, on the basis of the inflection point located at around $700 \mathrm{~nm}$ [5] (Fig. 11). The main spectral features referable to the application of this blend

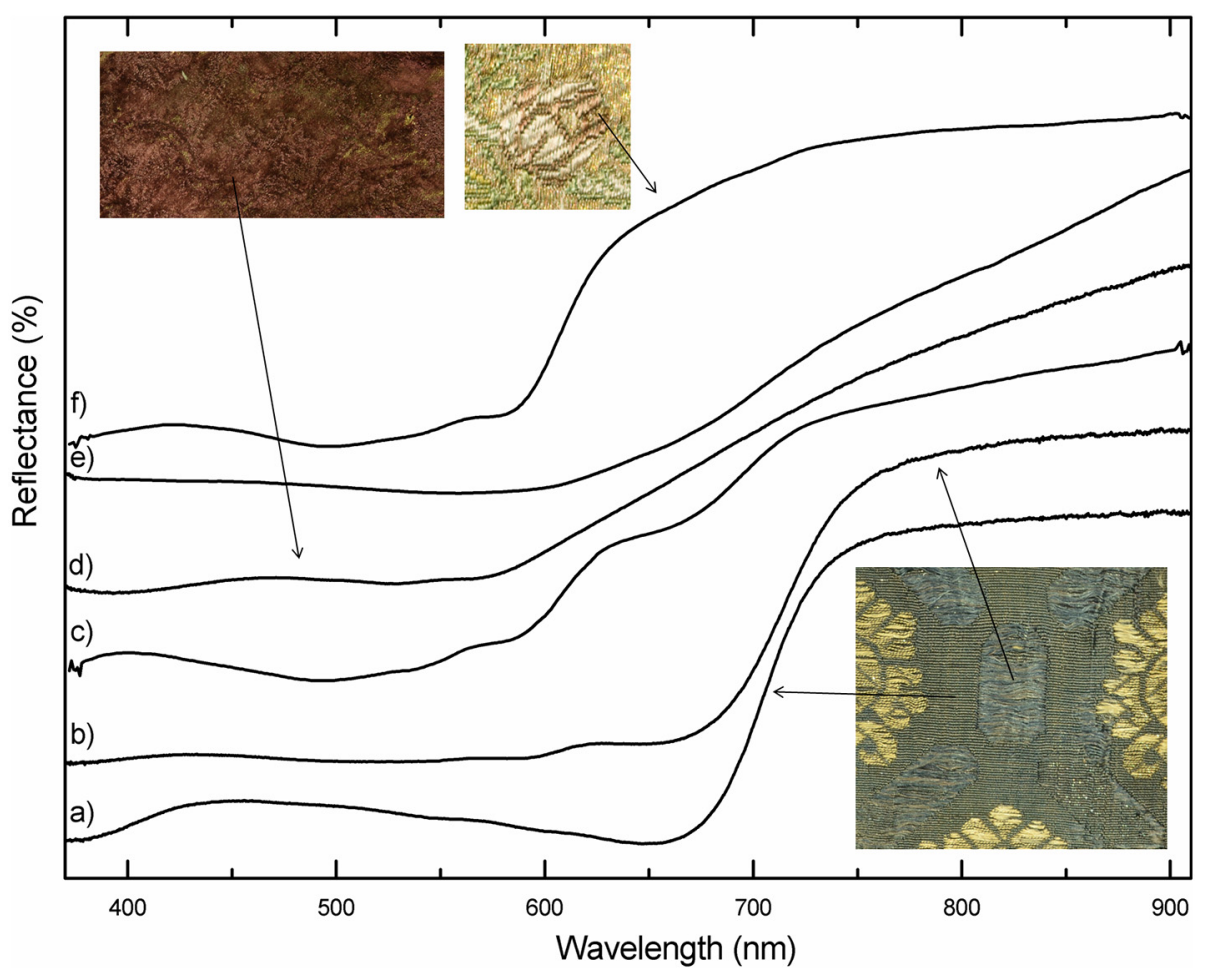

Fig. 11. Reflectance spectra of purple areas of samples: a) C1T4 front side; b) C1T4 back side; c) C1T9b; d) C2T1; e) C2T5; f) C1T9a. 
are reflectance maxima at about 432, 525, 564 and $622-628 \mathrm{~nm}$, as well as absorptions at about 592 and $660 \mathrm{~nm}$. When comparing collected spectra with literature data a general red-shift of exhibited profiles was generally observed, in particular the band centered at about 625 $\mathrm{nm}$, which was located at an intermediate position within those published by Gulmini et al. [11] for mixtures involving cochineal or madder. This behavior was assessed also for most of other examined purple areas: in Fig. 11c the case of sample C1T9b is reported, showing a slightly different shape attributable to a high amount of a red colorant. Other fragments exhibited reflectance profiles suggesting that the purple color was achieved by anthraquinones mordanted with suitable metallic salts, as found in samples C2T1, C2T5 and C1T9a (Fig. 11d-f). The first two spectra display reflectance bands centered at about 469, 510 and $550 \mathrm{~nm}$ and minima at 400, 526 and $569 \mathrm{~nm}$, respectively, looking very similar to those proposed by Gulmini et al. [11] for madder premordanted with alum. The very low reflectance displayed by sample C2T5 could be instead attributed to a relatively high concentration of colorant. Its related spectrum, reported in Fig. 11f, seems to match the profile reported for cochineal treated with alum [11], even if, as already pointed out, reflectance bands were shifted toward longer wavelengths also in this sample.

\subsection{Reflected-NIR Photography}

Reflected-Near Infrared imaging was employed with the aim to integrate data obtained by FORS measurements and to extend the investigated spectral range up to $1150 \mathrm{~nm}$ : only few reports [9,86,87] discuss the use of imaging techniques for the study of historical fabrics, in particular when addressed to a deeper characterization of natural dyes.

Acquired images were qualitatively compared with spectra from literature $[5,74]$ : as a general result, images could not allow the discrimination of colorants since a low absorption was generally observed for red, blue and yellow areas (Fig. 12a-d), compatible with the spectral behavior of anthraquinones, indigotin and flavonoids. On the contrary, dark brown areas displayed absorption (Fig. 12e$\mathrm{h}$ ) depending on the color intensity and probably due to dilution. This behavior is compatible with the use of tannins, whose spectra shows a gradual increase in the NIR interval [5]; further
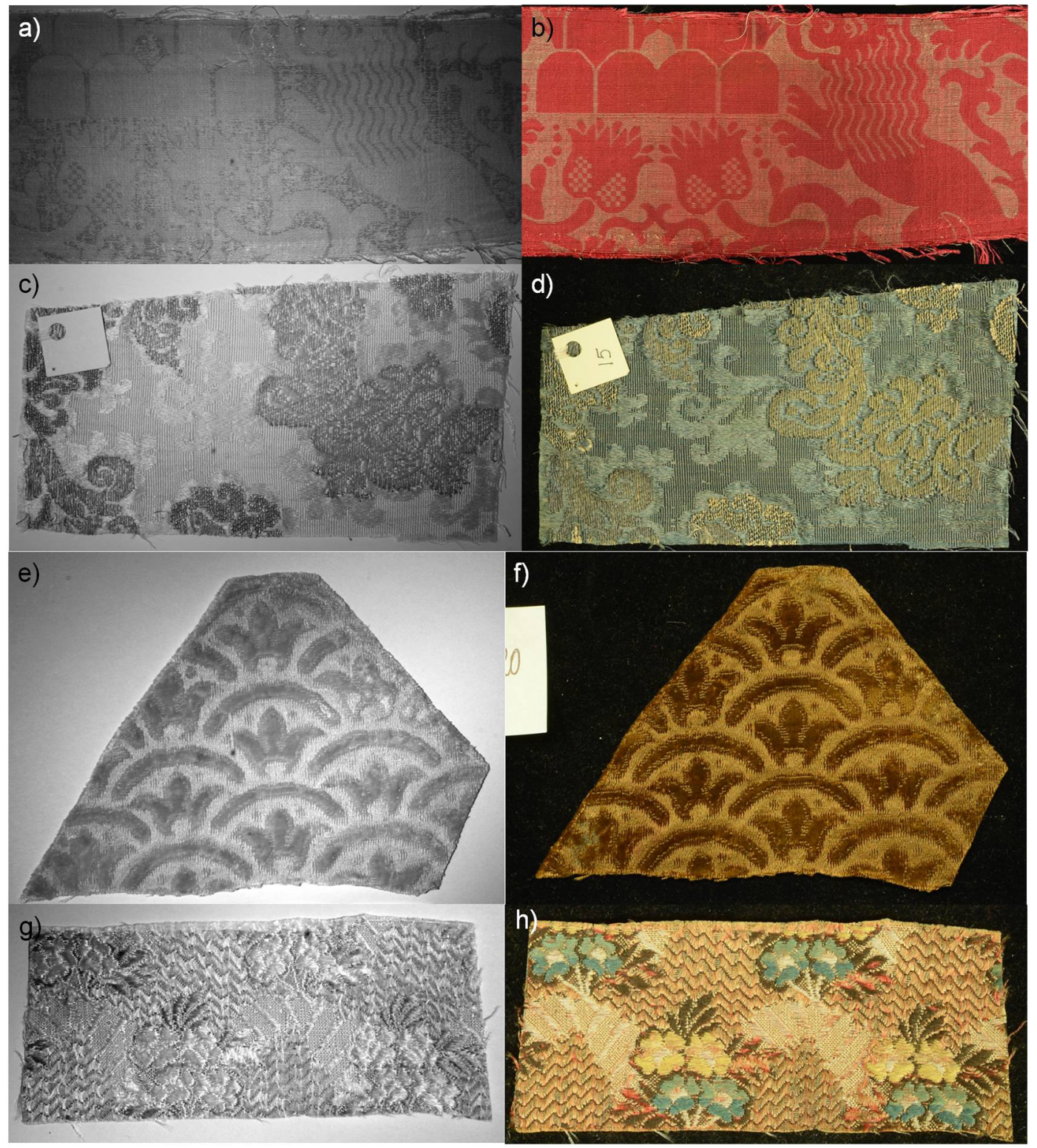

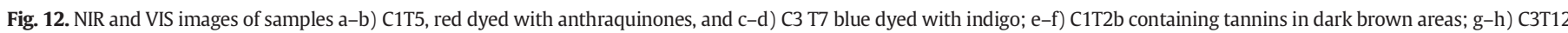
containing tannins in dark brown areas. 

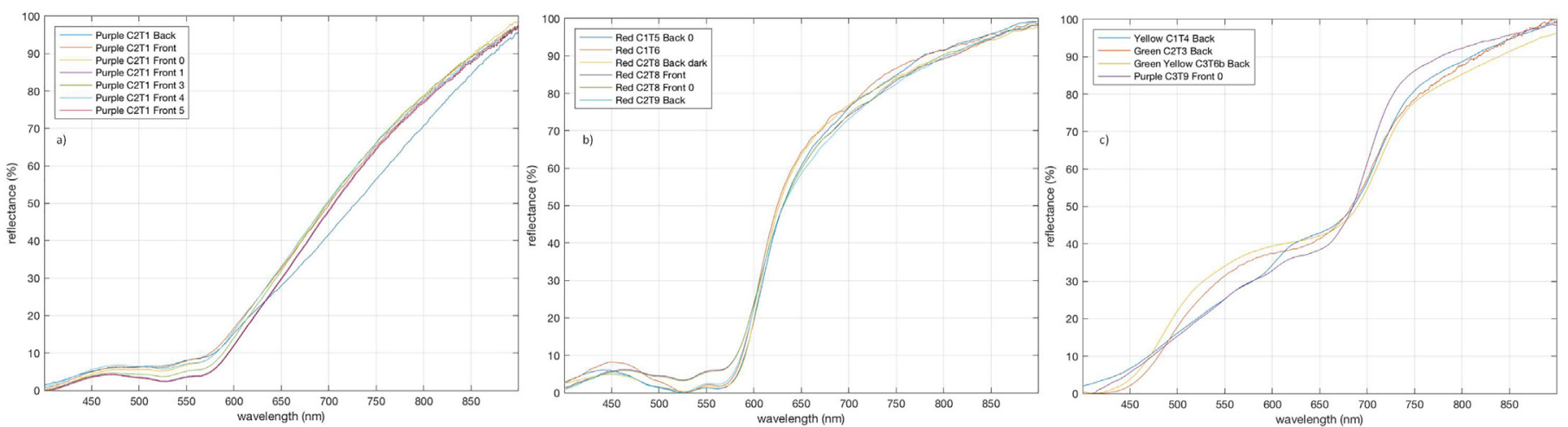

Fig. 13. Clustering of spectra in the $400-900 \mathrm{~nm}$ interval: a) cluster 6; b) cluster 14 ; c) cluster 20.

discriminations were not possible. The NIR investigation allowed confirming some attributions formulated on the basis of collected FORS spectra, but without adding further information to dyes characterization. Strong absorptions were detected in presence of metallic threads, while the use of silk as textile support, especially for some
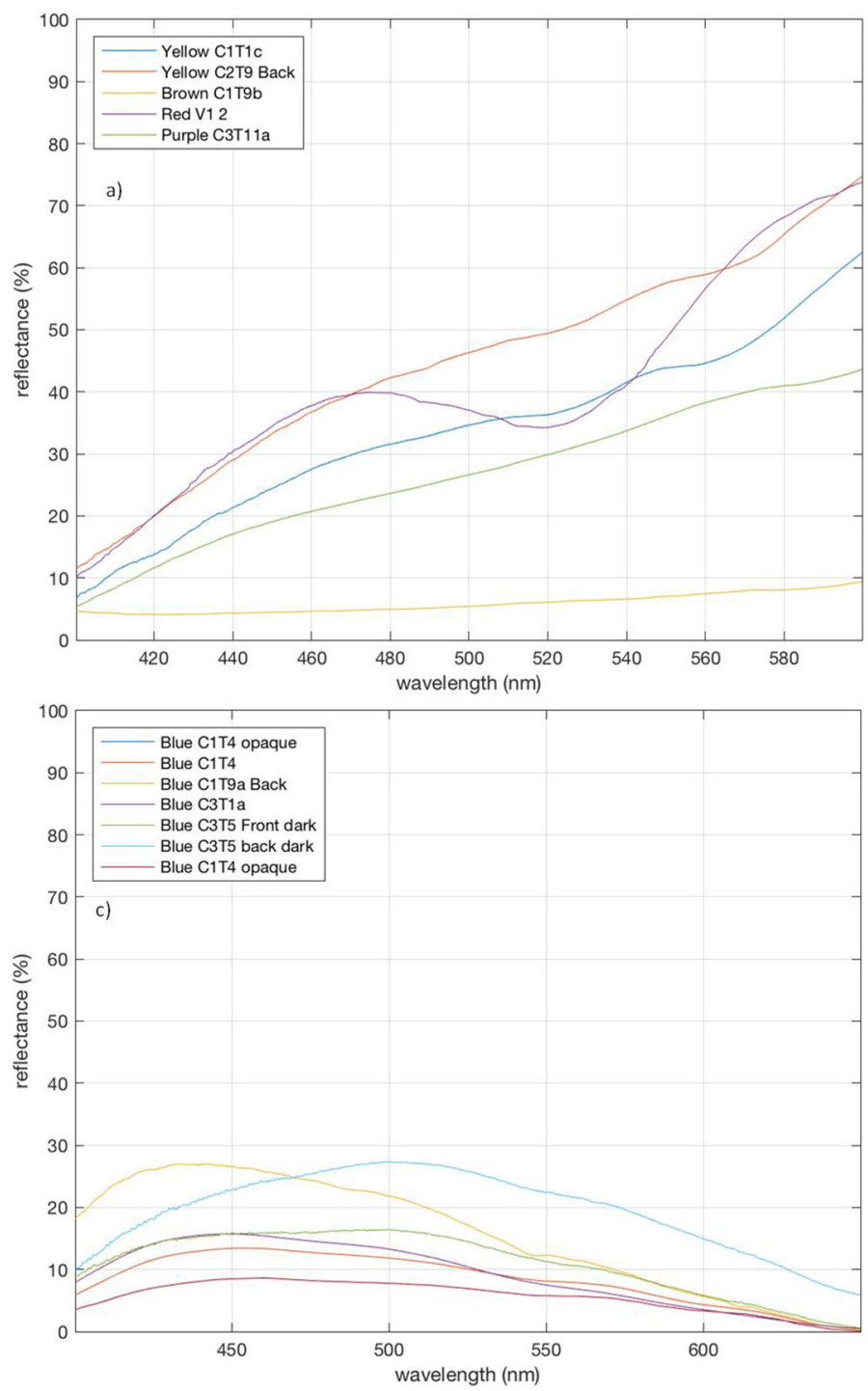

embroideries and manufactures, could have introduced "errors" due to the luster exhibited by such fibers. Furthermore, differences in IR radiation absorption within the captured surfaces can be related to dissimilar conservation conditions of the investigated fabrics (Figs. 12 a,b and e,f).
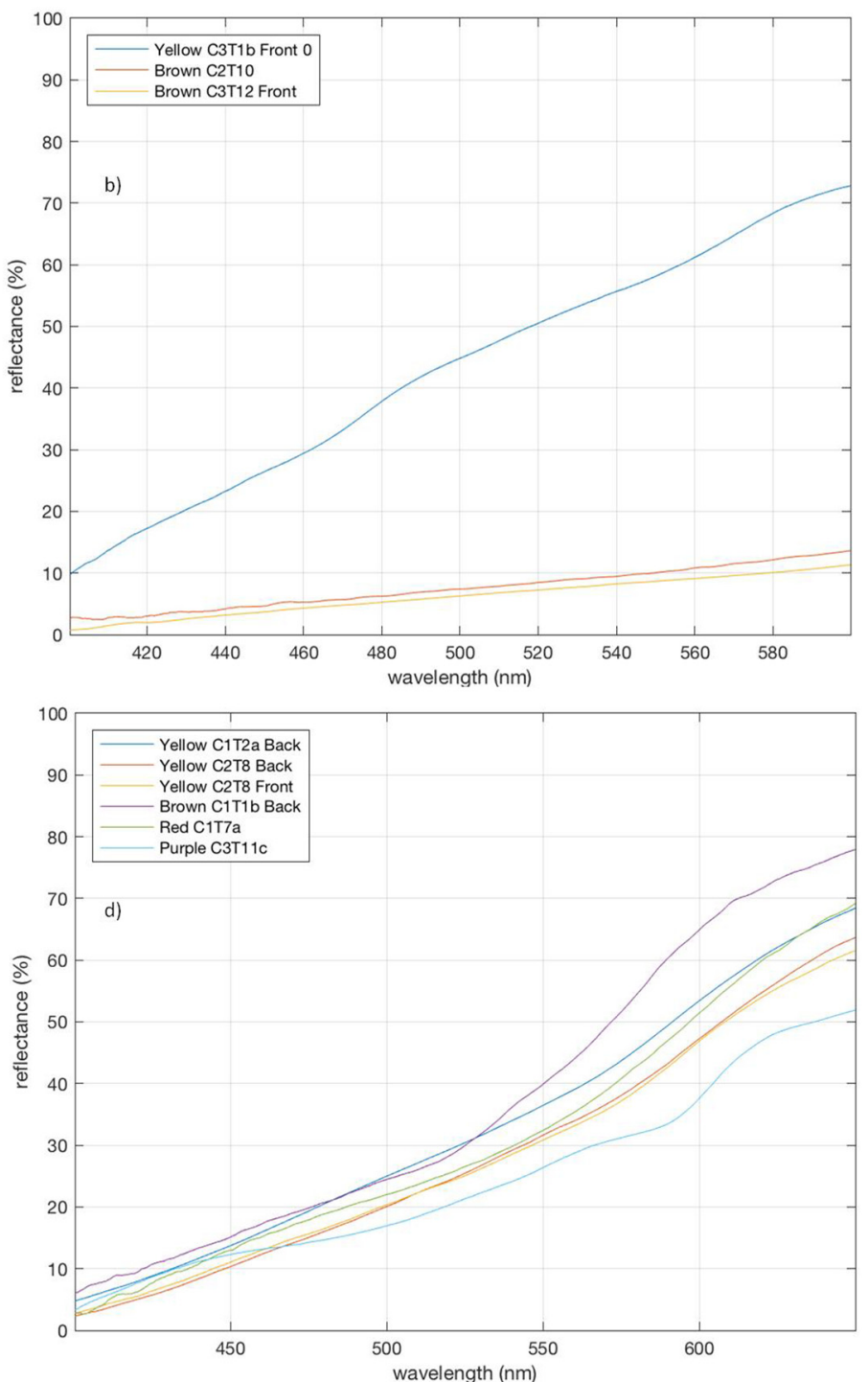

Fig. 14. Clustering of spectra in the $400-600 \mathrm{~nm}$ interval: a) cluster 26; b) cluster 28; and in the 400-650 nm interval: c) cluster 6; d) cluster 8 . 


\subsection{Clustering Analysis}

Despite the relative simplicity of reflectance spectroscopy, interpretation of acquired spectra based on a prompt attribution of exhibited spectral transitions is not straightforward. As a consequence, clustering analysis was applied to collected data-set to check if similarities in recorded spectra could lead to the same grouping of samples as obtained by a traditional comparison approach. The results showed that the number and composition of clusters changed when different constrains were applied, the most relevant being the considered spectral interval. The number of allowed clusters was fixed to 30 in order to limit the variability degree, since clusters of higher order were shown to contain very few spectra (generally no more than 3 ). In this way the algorithm discrimination capability could be compared when using different spectral ranges: the whole acquisition interval $(400-900 \mathrm{~nm})$ and narrower wavelength intervals (400-600, 400-650 and 400-700 nm). In this way the influence of spectral features resulted particularly relevant for the algorithm elaboration, and it was evaluated as the main inflection point positions due to indigotin and anthraquinones. This problem resulted mostly evident when elaborating whole spectra which were cut off at different wavelength values. While some of generated clusters resulted particularly homogeneous (Fig. 13a), in other cases discrepancies were only apparent, since notwithstanding differences in reflectance maxima positions, the absorption ones are consistent within the same cluster (Fig. 13b). As introduced above, the main inflection point position or the spectra slope resulted the dominant features, leading to the inclusion of anomalous profiles in the clusters or to an inconsistent grouping of spectra, as observed for cluster 20 (Fig. 13c).

Different clustering patterns were obtained when limiting spectra intervals at different wavelength values; the algorithm worked well in the 400-600 nm interval, with the only exceptions of C1T9a and C3T1b profiles in clusters 26 and 28, respectively (Fig. 14a, b). Cluster 26 resulted particularly inhomogeneous, with C1T9a profile as outlier; similarly, cluster 28 included two spectra of brown areas and a yellow one, mainly differentiable on the basis of their reflectance profiles in the considered spectral interval.

The main inflection point was included only for antraquinone-based dyes in the 400-650 nm spectral range. Also in this case some cluster displayed an apparent discrepancy since absorption positions corresponded for grouped spectra (es. cluster 6, Fig. 14c), while in other cases spectra containing mixed signals lead the algorithm to consider the dominant curve slope as the main grouping parameter instead of other spectral features. This process was not effective since it induced the clustering of quite different profiles, as in the case of cluster 8, where C1T1b and C3T11c spectra correspond to brown and purple threads sampled together with some yellow ones (Fig. 14d).

Finally, considering spectra limited at the $400-700 \mathrm{~nm}$ range a strong internal uniformity was found in many cases, even if generated a)

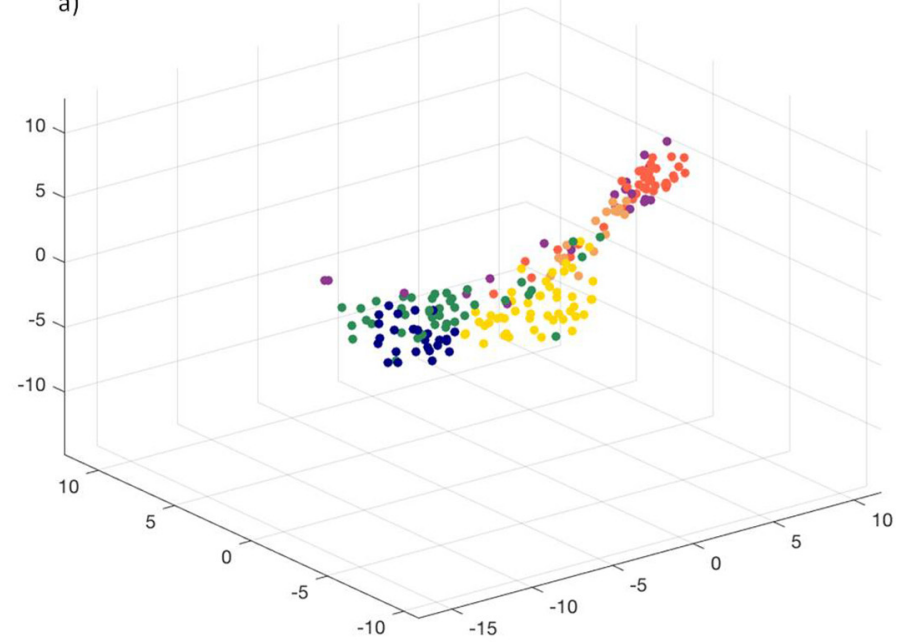

c)

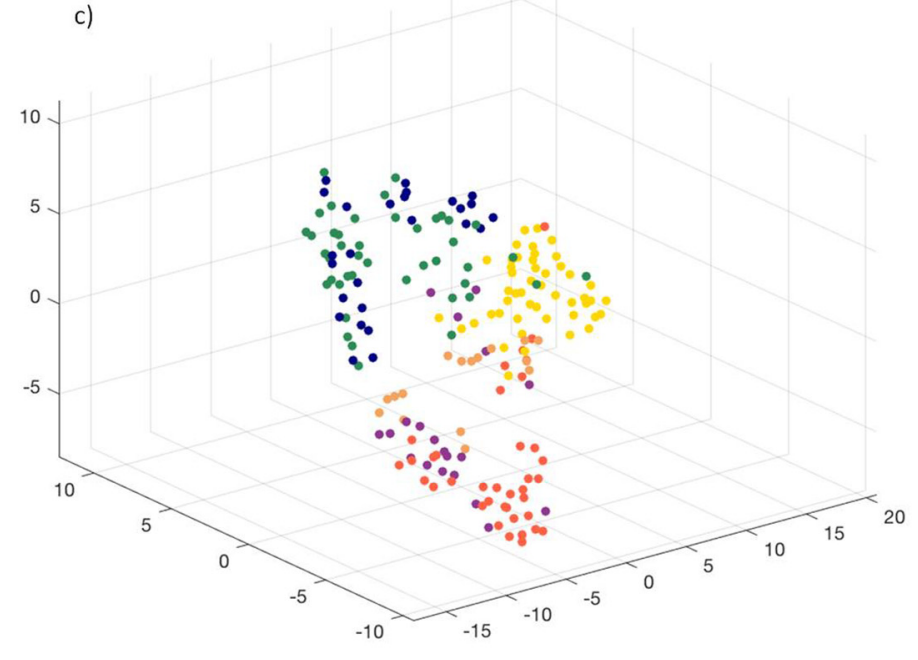

b)

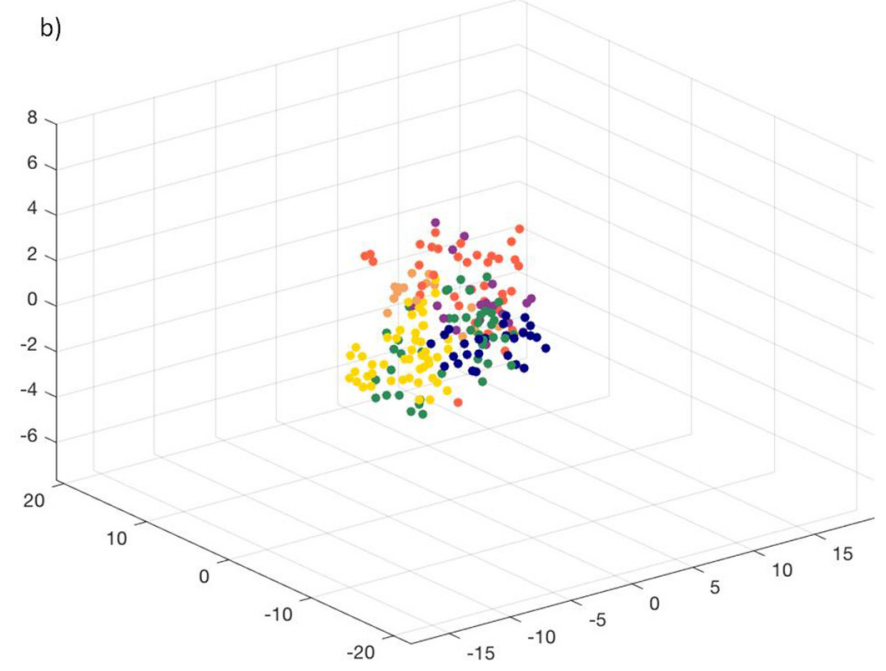

d)

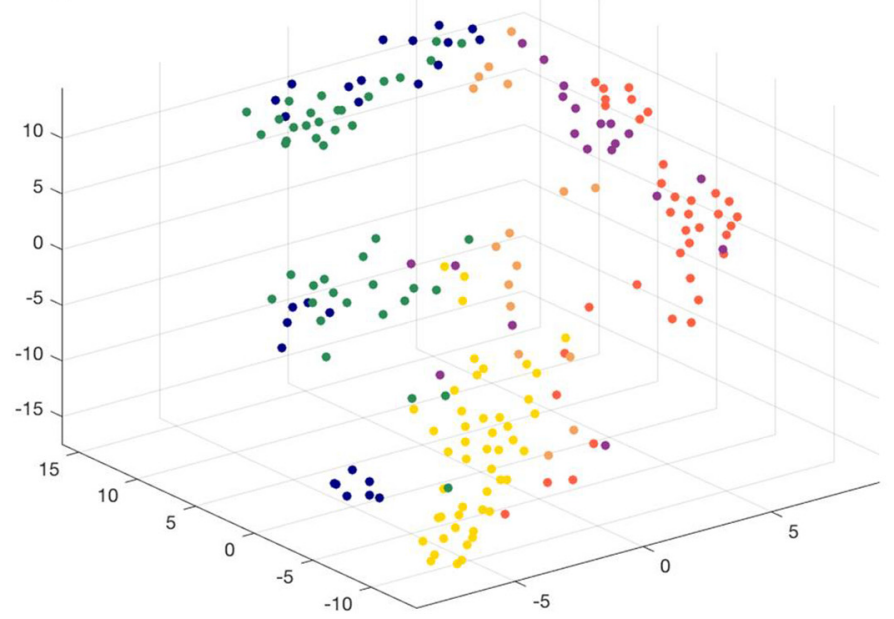

Fig. 15. Scatter plots obtained for clustering analysis in the a) 400-900 nm interval; b) 400-600 nm interval; c) $400-650 \mathrm{~nm}$ interval; d) $400-700 \mathrm{~nm}$ interval. 
groups included inconsistent profiles more often than with the previously considered special intervals, e.g. clusters 2, 11, 17, 22, 23 and 24 (the complete series of clustering data are reported as Supporting information 45-49).

The graphs reported in Fig. 15 resume datasets obtained for the 4 selected spectral intervals. The t-SNE [88] algorithm was applied in order to reduce spectra dimensions to 3 and to allow their visualization in a tridimensional space. Generated graphs clearly displayed differences existing within gathered reflectance spectra in terms of relative distances: data of whole spectra tended to separate in groups very close each other, avoiding a clear differentiation, especially within the same color hue (Fig. 15a). The pattern was much more confused when observing data obtained in the 400-600 nm interval (Fig. 15b), where many superimpositions arose, and the restricted spectral range did not allow discrimination of pure terms from mixtures. On the contrary, the discriminations obtained for the 400-650 and 400-700 nm range elaboration (Fig. 15c-d) resulted in well differentiated macro-groups where also color mixture positions are consistent with their dye compositions. In particular the superimposition of blue spectra and green ones indicate indigotin features as the dominant spectral components, as well as anthraquinones ones when studying most of purple spectra positions. Both elaborations showed that green/blue hues tend to separate into two main macro-groups, as well as the red/pink ones, and that purple hues are placed in an intermediate position between a red/pink cluster and a blue/green one.

\section{Conclusions}

This paper focused on a fully non-invasive study of a set of historical textile fragments coming from the wider collection assembled by Michelangelo Guggenheim by means of close-up and NIR-reflected imaging combined with Reflectance Spectroscopy.

Macrophotography in diffuse visible light provided detailed information about techniques employed to produce original textiles: warps, wefts and their intersections could be easily identified, together with two different kinds of metal threads inserted in some examined samples. Moreover, macrophotography proved to be a very useful tool in the examination of conservation conditions of historical fabrics, since holes and fractures not detectable by human eye could be easily inspected in detail. Such diffuse deteriorations highlighted a relatively bad state of conservation for most fragments.

Both Reflectance spectroscopy (FORS) and NIR-reflected photography were applied for the identification of dyes employed to color selected fabrics and their embroideries with a totally non-invasive and non-destructive approach. The FORS technique allowed obtaining basic preliminary information about colored artifacts, even if acquired spectra were not always easy to be interpreted since mixtures, the presence of metallic and/or differently colored threads, mordants, and other alterations affecting reflectance spectral features.

The use of traditional dyes from natural sources, whose use is compatible with examined fragments dating, was eventually assessed. Absorption bands enabled to attribute spectra acquired on blue areas to indigotin, those from brown hues to tannins, and allowed distinguishing spectra of anthraquinones-based dyestuffs from those ascribed to brazilwood. This was possible independently from the conservation state of examined areas, the mordant employed or the presence of metallic threads, and in some cases also from the presence of other dyestuffs. The possibility of discerning yellow dyestuffs resulted indeed much more limited, and only a very generic ascription to flavonoids was possible for investigated yellow areas. Finally, the comparison with literature suggested the employment of other yellow colorants such as turmeric or saffron in green mixtures. As a consequence, further micro-destructive analysis would be very useful for this specific class of compounds in order to confirm or correct hypothetical attributions reported in this work.
The acquisition of NIR images permitted to extend the investigated spectral range allowed by available FORS: the NIR absorbance behavior of selected fabrics confirmed the attributions provided by spectroscopic analysis, even being not adequate for colorants discrimination.

The application of clustering analysis on spectral data set was particularly relevant to identify which spectral features could lead to associate available spectra, such as inflection points or entire spectra. In this way, the proposed method could separate data into clusters allowing studying the spectra at group level. Furthermore, the process automatization was particularly useful since the availability of high-throughput technologies spectral data acquisition is currently growing. With the proposed method, it was possible to obtain clearer representation of data and to easily organize them into coherent groups, also recognizing anomalies in the acquisition process through the detection of outliers. Most evident observed anomalies concerned the generation of clusters including spectra from areas with differing colors but containing mixed spectral information due to the presence of very close threads with different colors; as consequence the possibility to better isolate them resulted crucial for the correct development of the algorithm.

This study allowed evidencing strength and weakness of a non-invasive and multi-technique approach for the characterization of natural dyes: the proposed method can be considered suitable when studying valuable ad delicate artifacts such as historical textiles, offering the possibility to rapidly acquire a large number of data without any damage to the investigated substrate. In this way an accurate study of colorants is possible, not only to determine the nature of dyeing materials, but also to properly guide further sampling for micro-destructive analysis. The obtained result will help to focus foreseen studies to solve specific problems related to the identification of yellow dyes and to the conservation of these fabrics.

Supplementary data to this article can be found online at https://doi. $\operatorname{org} / 10.1016 /$ j.saa.2018.06.026.

\section{Acknowledgments}

Authors gratefully acknowledge the financial support of Madatec srl (Pessano con Bornago, MI, Italy) to the present investigation. Authors are deeply indebted to the "M. Guggenheim" Art High School of Venice for allowing the current study on their fabrics collection. Authors acknowledge moreover Prof. D. Davanzo Poli (University Ca' foscari of Venice, Italy) for her support in the identification of textiles dating, typology and origin.

Authors are also grateful to Dr. D. Marchetto and to F. Agnoletto (University Ca' Foscari of Venice, Italy) for their support in collecting colorimetric data and reflected NIR-imaging, respectively.

\section{References}

[1] M. Bacci, F. Baldini, R. Carlà, L. Linari, A color analysis of the Brancacci Chapel frescoes, Appl. Spectrosc. 45 (1991) 26-31.

[2] M. Bacci, S. Baronti, A. Casini, F. Lotti, M. Picollo, Nondestructive spectroscopic investigations on paintings using optical fibers, Materials Issues in Art and Archaeology III, Materials Research Society Symposium Proceedings, Materials Research Society, San Francisco, California 1992, pp. 265-283.

[3] E. Cheilakou, M. Troullinos, M. Koui, Identification of pigments on Byzantine wall paintings from Crete (14th century AD) using non-invasive Fiber Optics Diffuse Reflectance Spectroscopy (FORS), J. Archaeol. Sci. 41 (2014) 541-555.

[4] S. Bruni, S. Caglio, V. Guglielmi, G. Poldi, The joined use of n.i. spectroscopic analyses - FTIR, Raman, visible reflectance spectrometry and EDXRF - to study drawings and illuminated manuscripts, Appl. Phys. A Mater. Sci. Process. 92 (2008) 103-108.

[5] M. Aceto, A. Agostino, G. Fenoglio, A. Idone, M. Gulmini, M. Picollo, P. Ricciardi, J.K. Delaney, Characterisation of colourants on illuminated manuscripts by portable fibre optic UV-visible-NIR reflectance spectrophotometry, Anal. Methods 6 (2014) 1488-1500.

[6] T. Miyoshi, Y. Matsuda, Laser-induced fluorescence and optical reflection spectra of Japanese natural dyes on silk, Jpn. J. Appl. Phys. 26 (1987) 239-245.

[7] C. Clementi, W. Nowik, A. Romani, F. Cibin, G. Favaro, A spectrometric and chromatographic approach to the study of ageing of madder (Rubia tinctorum L.) dyestuff on wool, Anal. Chim. Acta 596 (2007) 46-54. 
[8] R. Nakamura, Y. Tanaka, A. Ogata, M. Naruse, Dye analysis of Shosoin textiles using excitation-emission matrix fluorescence and ultraviolet-visible reflectance spectroscopic techniques, Anal. Chem. 81 (2009) 5691-5698.

[9] F. Pozzi, G. Poldi, S. Bruni, E.D. Luca, V. Guglielmi, Multi-technique characterization of dyes in ancient Kaitag textiles from Caucasus, Archaeol. Anthropol. Sci. 4 (2012) 185-197.

[10] L.G. Angelini, S. Tozzi, S. Bracci, F. Quercioli, B. Radicati, M. Picollo, Characterization of traditional dyes of the Mediterranean area by non-invasive uv-vis-nir reflectance spectroscopy, Stud. Conserv. 55 (Suppl. 2) (2010) 184-189.

[11] M. Gulmini, A. Idone, E. Diana, D. Gastaldi, D. Vaudan, M. Aceto, Identification of dyestuffs in historical textiles: strong and weak points of a non-invasive approach, Dyes Pigments 98 (2013) 136-145.

[12] M.A. Maynez-Rojas, E. Casanova-González, J.L. Ruvalcaba-Sil, Identification of natural red and purple dyes on textiles by fiber-optics reflectance spectroscopy, Spectrochim. Acta A 178 (2017) 239-250.

[13] R. Mongkholrattanasit, J. Krystufek, J. Wiener, M. Vikova, Dyeing, fastness, and UV protection properties of silk and wool fabrics dyed with eucalyptus leaf extract by the exhaustion process, Fibres Text. East. Eur. 3 (2011) 94-99.

[14] P. Garside, P. Wyeth, X. Zhang, Understanding the ageing behaviour of nineteenth and twentieth century tin-weighted silks, J. Inst. Conserv. 33 (2010) 179-193.

[15] H.E. Ahmed, S.S. Darwish, Effect of museum conditions on historical dyed silk fabric with madder dye, J. Polym. Environ. 20 (2012) 596-606.

[16] C. Septhum, V. Rattanaphani, R. Rattanaphani, Uv-vis spectroscopic study of natural dyes with alum as a mordant, Suranaree J. Sci. Technol. 14 (2007) 91-97.

[17] A.P. Agati, M.C. Coldagelli, C. Consoni, C. Merucci, G. Minunno, A. Rorro, I. Serafini, N. Torrioli, I Supporti Nelle Arti Pittoriche: Storia, Tecnica, Restauro, Ugo Mursia, Milano, 1990.

[18] Archivio di Stato di Venezia, Fondo Papadopoli, busta 245, Lettera di Jacob Levi \& figli, firmata da Alessandro Levi, a Ephrussi \& Porgès e Erzberger \& fils, del 13 giugno1881.

[19] Marchands étrangers, Agenda de la Curiosité des artistes et des amateurs1889 204-205.

[20] Lettera di Giovanni Morelli a Giovanni Melli del 9 gennaio 1872, in: J. Anderson (Ed.), Collecting connoisseurship and the art market in Risorgimento Italy. Giovanni Morelli's Letters to Giovanni Melli and Pietro Zavaritt (1866-1872), La Garangola, Padova 1999, pp. 143-146.

[21] A. Martignon, Michelangelo Guggenheim e le arti decorative, Saggi e memorie di storia dell'arte 39 2017, pp. 46-71

[22] A. Martignon, Michelangelo Guggenheim (1837-1914) e il mercato di opere, di oggetti d'arte e d'antichità a Venezia fra medio Ottocento e primo Novecento, (PhD Thesis) Università degli Studi di Udine, 2015.

[23] Guide commerciali di Venezia from 1878 to $1910-1911$.

[24] E. Marini, Venezia antica e moderna, Tip. F. Visentini, Venezia, 1905

[25] Archivio privato, Nota manoscritta di Michelangelo Guggenheim del 15 agosto 1902.

[26] Archivio Storico dell'Accademia di Belle Arti di Venezia, Ufficio per le licenze d'esportazione d'oggetti d'arte (1871-1896); Archivio Centrale dello Stato, Roma, Ministero della Pubblica Istruzione, Direzione Generale di Antichità e Belle Arti.

[27] I. Errera, Collection d'Anciennes Étoffes. Catalogue, Falk Fils, Bruxelles, 1901 23,24, $81,113,114$.

[28] I. Errera, Musées Royaux des Arts Décoratifs de Bruxelles. Catalogue d'Étoffes anciennes et modernes, Lamertin, Bruxelles, 1907 46,47, 128, 175,176.

[29] E. M. B., Michelangelo Guggenheim, L'Adriatico (21 September 1915) 3.

[30] M. E. E. Guest Layard, Journals, 29 November 1886. https://pops.baylor.edu/layard/ xml.php?fn=18861129.xml (accessed 19 April 2018).

[31] M. E. E. Guest Layard, Journals, 13 January 1887. https://pops.baylor.edu/layard/xml. php?fn=18870113.xml (accessed 19 April 2018).

[32] M. E. E. Guest Layard, Journals, 15 January 1887. https://pops.baylor.edu/layard/xml. php?fn=18870115.xml (accessed 19 April 2018).

[33] Archivio Storico dell'Accademia di Belle Arti di Venezia, Ufficio per le licenze d'esportazione d'oggetti d'arte (1871-1896), cartella 11, Richiesta di esportazione in carta bollata di Michelangelo Guggenheim, firmata da G. Moro, agente della galleria, del 23 novembre 1891; Licenza di esportazione di Michelangelo Guggenheim, firmata da G. Moro, agente della galleria, del 23 novembre 1891 .

[34] Archivio di Stato di Venezia, Fondo Papadopoli, buste 137, 245.

[35] R. Erculei, Museo Artistico Industriale, Roma, Esposizioni retrospettive e contemporanee di industrie artistiche. Esposizione del 1887. Tessuti e merletti. Catalogo delle opere esposte con brevi cenni sull'arte tessile in Italia, Stab. G. Civelli, Roma, 1887.

[36] I. Chiappini di Sorio, Stoffe antiche della collezione Guggenheim al Museo Correr, Stamperia di Venezia, Venezia, 1970.

[37] I. Chiappini di Sorio, Le stoffe copte del Museo Correr, Boll. dei Musei Civ. Veneziani 1-2 (1975) 9-31.

[38] S. Moronato, I. Chiappini di Sorio, A. Zaccaria Ruggiu, M. Cuoghi Costantini, I. Silvestri, D. Davanzo Poli, Una città e il suo museo. Un secolo e mezzo di collezioni civiche veneziane, exhibition catalogue, Boll. dei Civ. Musei Veneziani d'Arte e di Storia 1-4 (1988) 205-247.

[39] F. Boscolo Marchi, La piccola collezione di tessuti copti di Michelangelo Guggenheim, (Bachelor Thesis) Università Ca' Foscari di Venezia, 2002.

[40] L. Tasso, Michelangelo Guggenheim e le Civiche Raccolte di Venezia, (Specialization School Thesis) Università degli Studi di Padova, 2011.

[41] L. Tasso, Michelangelo Guggenheim e le Civiche Raccolte veneziane, Bozzetti e modelli di Giovanni Maria Morlaiter nelle collezioni dei Musei Civici Veneziani, Boll. dei Musei Civ. Veneziani 6 (2011) 136-141.

[42] F. Sacchetto, Gusto e collezionismo dei merletti a Venezia nella prima metà del Novecento. Una ricognizione nel fondo Correr, (Master Thesis) Università Ca' Foscari di Venezia, 2013.
[43] M. Messina, I tessuti di Michelangelo Guggenheim presso i Civici Musei di Storia ed Arte di Trieste, (Specialization School Thesis) Università degli Studi di Pisa, 2000.

[44] M. Messina, Un'inedita raccolta tessile nei Musei Civici di Trieste: la Collezione Guggenheim, Polittico 2002, pp. 115-129.

[45] M. Messina, Il "campionario di stoffe antiche dei secoli passati" donato da Michelangelo Guggenheim nel 1891: analisi di una collezione e note sull'attività della Società degli Amici dell'Arte nella Trieste di fine '800, Atti dei Civ. Musei di Storia ed Arte di Trieste, 22, 2011, pp. 475-522.

[46] Archivio privato, Inventario della raccolta di tessuti di Michelangelo Guggenheim, ms.

[47] L'appartamento d'onore di casa Papadopoli, Gazzetta di Venezia (22 February 1882) 2.

[48] C. Oleari, Misurare il colore, Hoepli, Milano, 1998

[49] M. Pavan, M. Pelillo, Dominant sets and pairwise clustering, IEEE Trans. Pattern Anal. Mach. Intell. 29 (2007) 167-172.

[50] E. Aykut, M. Pelillo, Graph transduction as a noncooperative game, Neural Comput 24 (3) (2012) 700-723.

[51] R. Tripodi, M. Pelillo, A game-theoretic approach to word sense disambiguation, Comput. Linguist. 43.1 (2017) 31-70.

[52] R.O. Duda, P.E. Hart, D.G. Stork, Pattern Classification, Wiley ed., New York, 1973.

[53] P.D. Taylor, L.B. Jonker, Evolutionarily stable strategies and game dynamics, Math. Biosci. 40 (1978) 145-156.

[54] T. Kanungo, D.M. Mount, N.S. Netanyahu, C.D. Piatko, R. Silverman, A.Y. Wu, An efficient k-means clustering algorithm: analysis and implementation, IEEE Trans. Pattern Anal. Mach. Intell. 24 (7) (2002) 881-892.

[55] W. Zhenyu, R. Leahy, An optimal graph theoretic approach to data clustering: theory and its application to image segmentation, IEEE Trans. Pattern Anal. Mach. Intell. 15 (11) (1993) 1101-1113.

[56] A. Karatzani, T. Rehren, The use of metal threads and decorations in ByzantineGreek orthodox ecclesiastical textiles, JOM 58 (2006) 34-37.

[57] M. Bergstrand, E. Hedhammar, European metal threads in Swedish churches 1600 1751: construction and conservation, Stud. Conserv. 51 (2006) 11-28.

[58] Teofilo Monaco, in: A. Caffaro (Ed.), Le varie arti - De diversis artibus Manuale di tecnica artistica medievale, Palladio Editrice, Salerno, 2000.

[59] V. Biringuccio, in: C.S. Smith, M.T. Gnudi (Eds.), The Pirotechnia of Vannoccio Biringuccio: The Classic Sixteenth-century Treatise on Metals and Metallurgy, Dover Publications, New York, 1990.

[60] P. Cox Crew, The influence of mordant on the lightfastness of yellow natural dyes, J. Am. Inst. Conserv. 21 (1982) 43-58.

[61] T. Padfield, S. Landi, The light-fastness of the natural dyes, Stud. Conserv. 11 (1966) 181-196.

[62] B.L. Ford, Monitoring colour change in textiles on display, Stud. Conserv. 37 (1992) $1-11$.

[63] J.M. del Hoyo-Meléndez, M.F. Mecklenburg, Micro-fading spectrometry: a tool for real-time assessment of the light-fastness of dye/textile systems, Fibers Polym. 13 (2012) 1079.

[64] M. Saltzman, Identifying dyes in textiles, Am. Sci. 80 (1992) 474-481.

[65] M. Leona, J. Winter, Fiber optics reflectance spectroscopy: a unique tool for the investigation of Japanese paintings, Stud. Conserv. 46 (2001) 153-162.

[66] I. Karapanagiotis, D. Mantzouris, P. Kamaterou, D. Lampakis, C. Panayiotou, Identification of materials in post-Byzantine textiles from Mount Athos, J. Archaeol. Sci. 38 (2011) 3217-3223.

[67] S. Acquaviva, E. D'Anna, M.L. De Giorgi, A. Della Patria, M. Fantuzzi, Colour stability and performance of vegetal dyes on natural fibres, J. Int. Colour Assoc. 8 (2012) 2-9.

[68] A.R. Monahan, J.E. Kuder, Spectroscopic differences between crystalline and amorphous phases of indigo, J. Organomet. Chem. 37 (1972) 4182-4184.

[69] A. Amat, F. Rosi, C. Miliani, A. Sgamellotti, S. Fantacci, Theoretical and experimenta investigation on the spectroscopic properties of indigo dye, J. Mol. Struct. 993 (2010) 43-51.

[70] D. Cristea, G. Vilarem, Improving light fastness of natural dyes on cotton yarn, Dyes Pigments 70 (2006) 238-245.

[71] P.M. Whitmore, G.R. Cass, J.R. Druzik, The ozone fading of traditional natural organic colorants on paper, J. Am. Inst. Conserv. 26 (1987) 45-57.

[72] D. Grosjean, P.M. Whitmore, G.R. Cass, J.R. Druzik, Ozone fading of natural organic colorants: mechanisms and products of the reaction of ozone with indigos, Environ. Sci. Technol. 22 (1988) 292-298.

[73] A. El Bakkali, T. Lamhasni, M. Haddad, S. Ait Lyazidi, S. Sanchez-Cortes, E. del Puerto Nevado, Non-invasive micro Raman, SERS and visible reflectance analyses of coloring materials in ancient Moroccan Islamic manuscripts, J. Raman Spectrosc. 44 (2013) 114-120

[74] A.V. Whitney, R.P. Van Duyne, F. Casadio, An innovative surface-enhanced Raman spectroscopy (SERS) method for the identification of six historical red lakes and dyestuffs, J. Raman Spectrosc. 37 (2006) 993-1002.

[75] D. Marmion, Colorants for food, in: K. Othmer (Ed.), Food and Feed Technology, Wiley ed., Hoboken 2008, pp. 228-318.

[76] T. Vitorino, A. Casini, C. Cucci, M.J. Melo, M. Picollo, L. Stefani, Non-invasive identification of traditional red lake pigments in fourteenth to sixteenth centuries paintings through the use of hyperspectral imaging technique, Appl. Phys. A Mater. Sci. Process. 121 (2015) 891-901.

[77] C. Bisulca, M. Picollo, M. Bacci, D. Kunzelman, Uv-vis-nir reflectance spectroscopy of red lakes in paintings, 9th International Conference on NDT of Art, Jerusalem 2008, pp. $1-8$.

[78] H. Kunkely, A. Vogler, Absorption and luminescence spectra of cochineal, Inorg Chem. Commun. 14 (2011) 1153-1155.

[79] T. Vitorino, A. Casini, C. Cucci, M.J. Melo, M. Picollo, L. Stefani, Hyper-spectral acquisition on historically accurate reconstructions of red organic lakes, in: A. Elmoataz, 
O. Lezoray, F. Nouboud, D. Mammass (Eds.), Image and Signal Processing ICISP 2014 Lecture Notes in Computer Science, 8509, Springer Cham., Switzerland 2018 pp. 257-264.

[80] E.S.B. Ferreira, A.N. Hulme, H. McNab, A. Quye, The natural constituents of historica textile dyes, Chem. Soc. Rev. 33 (2004) 329-336.

[81] T.J. Mabry, K.R. Markham, M.B. Thomas, The Systematic Identification of Flavonoids, Springer-Verlaged, New York, 1970.

82] V. Chedea, S.I. Vicas, C. Socaciu, T. Nagaya, HJ.O Ogola, K Yokota, K. Nishimura, M. Jisaka, Lipoxygenase-quercetin interaction: A kinetic study through biochemical and spectroscopy approaches, in: J.C. Jimenez-Lopez (Ed.), Biochemical Testing, InTech, London, 2012.

[83] P. Valipur, E. Ekrami, A. Shams-Nateri, Colorimetric properties of wool dyed with cochineal: effect of dye-bath pH, Prog. Color Color. Coat. 7 (2014) 129-138.
[84] F. Brunello, L'arte Della Tintura Nella Storia Dell'umanita, Neri Pozza ed, Vicenza, 1968.

[85] I. Degano, E. Ribechini, F. Modugno, M.P. Colombini, Analytical methods for the characterization of organic dyes in artworks and in historical textiles, Appl. Spectrosc. Rev. 44 (2009) 363-410.

[86] C. Baldia, Development of a Protocol to Detect and Classify Colorants in Archaeological Textiles and its Application to Selected Prehistoric Textiles from Seip Mound in Ohio, (PhD Thesis) Ohio State University, 2005.

[87] C.M. Baldia, K.A. Jakes, Photographic methods to detect colourants in archaeological textiles, J. Archaeol. Sci. 34 (2007) 519-525.

[88] L.V.D. Maaten, G. Hinton, Visualizing data using t-SNE, J. Mach. Learn. Res. 9 (2008) 2579-2605. 